\title{
The fifth cranial nerve in headaches
}

\author{
J. C. A. Edvinsson 1,2* (D, A. Viganò ${ }^{3}$, A. Alekseeva ${ }^{4}$, E. Alieva ${ }^{5}$, R. Arruda ${ }^{6}$, C. De Luca ${ }^{7,8}$ N. D'Ettore 9 , I. Frattale ${ }^{10}$, \\ M. Kurnukhina ${ }^{11,12}$, N. Macerola ${ }^{13}$, E. Malenkova ${ }^{14}$, M. Maiorova ${ }^{15}$, A. Novikova ${ }^{16}$, P. Řehulka ${ }^{17}$, V. Rapaccini ${ }^{18,19,20}$, \\ O. Roshchina ${ }^{4}$, G. Vanderschueren ${ }^{21}$, L. Zvaune $22,23,24$, A. P. Andreou ${ }^{25,26}$, K. A. Haanes ${ }^{1}$ and On behalf of the \\ European Headache Federation School of Advanced Studies (EHF-SAS)
}

\begin{abstract}
The fifth cranial nerve is the common denominator for many headaches and facial pain pathologies currently known. Projecting from the trigeminal ganglion, in a bipolar manner, it connects to the brainstem and supplies various parts of the head and face with sensory innervation. In this review, we describe the neuroanatomical structures and pathways implicated in the sensation of the trigeminal system. Furthermore, we present the current understanding of several primary headaches, painful neuropathies and their pharmacological treatments. We hope that this overview can elucidate the complex field of headache pathologies, and their link to the trigeminal nerve, to a broader field of young scientists.
\end{abstract}

Keywords: Fifth cranial nerve, Trigeminal ganglion, Headache, CGRP, Treatments, Migraine pathophysiology

\section{Introduction}

Considering that the classification of headache disorders (ICHD-3) contains almost 300 different types of headaches and facial pains [1], it is quite surprising that a large part of pathophysiological mechanisms rely on the same anatomical basis. Since the early work by Harold Wolff and his contemporaries [2] it has been shown that, among intracranial structures, only the dura mater, its vessels and the cerebral blood vessels are pain sensitive and can show referred pain on various extracranial positions [3]. This classical view was recently expanded by an observational study [4] to include pia mater and its cortical arterioles as potential pain sensitive structures. Subsequent neuroanatomical and neurochemical studies revealed that most sensory fibres from the intracranial and the extracranial tissues originate in the fifth cranial nerve $(\mathrm{CN} \mathrm{V})$ ganglion, also called trigeminal ganglion

\footnotetext{
*Correspondence: jacob.edvinsson@sund.ku.dk

'Department of Clinical Experimental Research, Glostrup Research Institute, Rigshospitalet Glostrup, 2600 Glostrup, Denmark

${ }^{2}$ Department of Drug Design and Pharmacology, Faculty of Health and Medical Sciences, University of Copenhagen, Copenhagen, Denmark Full list of author information is available at the end of the article
}

(TG). However, not all intracranial sensory fibers are trigeminal. For example, the posterior cranial fossa, is mainly innervated by the occipital nerves.

Depending on which part of the head is innervated the fibres can be traced back to different parts of the TG [5]. In general, headache pain is referred to a cutaneous territory area on the scalp, sharing supply with a nerve innervating the intracranial area, which might be the actual source of pain. Similarly, pain can be referred to a different territory than the actual nerve receiving the painful stimulation. This can happen if the two nerves share a high-order neuron (a process called "convergence").

Primary headaches comprise the most prevalent group of neurological disorders. Among these, migraine is estimated to be present in $14.4 \%$ of the global population [6]. The WHO ranks migraine as the most prevalent, disabling, long-term neurological condition when taking into account years lost due to disability in young individuals $[7,8]$. The burden on individuals and society is enormous [9], especially if other headaches such as tension-type $(\mathrm{TTH})$, the second more common disorder worldwide $[7,8]$, and medication-overuse headache 
$(\mathrm{MOH})$ are taken into account. Though TTH is more prevalent (26.1\%) [6], migraine is the more debilitating, as migraine has been reported to contribute $16.3 \%$ of disability-adjusted life-years on the global burden of neurological disorders [10]. The present work is a comprehensive description of various aspects of the $\mathrm{CN} \mathrm{V}$, the largest of the cranial nerves. Its more common name "trigeminal" (triplet) derives from its clearly visible division into three main branches (Fig. 1). In this review we explore the trigeminal nerve, its related pain conditions and current treatments to emphasize its importance to headache pathophysiology.

\section{The Trigeminovascular system}

The vascular system of the head, face, meninges and the brain have a variable innervation of autonomic and sensory nerves [12]. In general, the arterial system is richly supplied with sensory nerves whereas the veins are weakly innervated. Capillaries are not innervated. For the cerebral vasculature, it is different; while the pial or extracerebral arterial system is richly supplied, once the vessels penetrate into the brain parenchyma their autonomic and sensory fibres disappear (at the level of the space of Virchow), as these are regulated by metabolic demand [13].

The trigeminovascular system has long been a focus of elucidating primary headache pathophysiology [14]. It consists of the trigeminal neurons innervating the cerebral arteries, the pial and dural blood vessels, and sinuses [15]. Nociceptive activation of $\mathrm{C}$ - and $\mathrm{A} \delta$-fibres innervating these structures is thought to be involved in the headache phase of migraine. The cranial dura mater nerve fibres are mainly supplied by the ophthalmic branch (V1), though collaterals from the maxillary branch (V2), the mandibular branch (V3) and cervical root ganglion provide dural innervation to smaller caudal regions. Afferents from the TG carry this nociceptive information into the brainstem where they mainly terminate at second order neurons inhabiting the trigeminocervical complex (TCC) [15].

Studies have shown that parts of the trigeminovascular system (notably TG) lack blood-brain barrier (BBB) and has been hypothesized being the target tissue where some anti-migraine drugs (e.g. monoclonal antibodies, gepants, triptans) elicit their effects [16]. Because of this evidence it is likely that $\mathrm{CN} \mathrm{V}$ is an integral part in understanding headache pathophysiology [17].

\section{The trigeminal ganglion}

Shortly after CN V protrudes from each side of the superior lateral pons the TG can be found residing in each of Meckel's caves (Fig. 2). The TG has been termed a "central hub" in the trigeminovascular transmitting pathway as it contains the soma of the peripheral nerves able

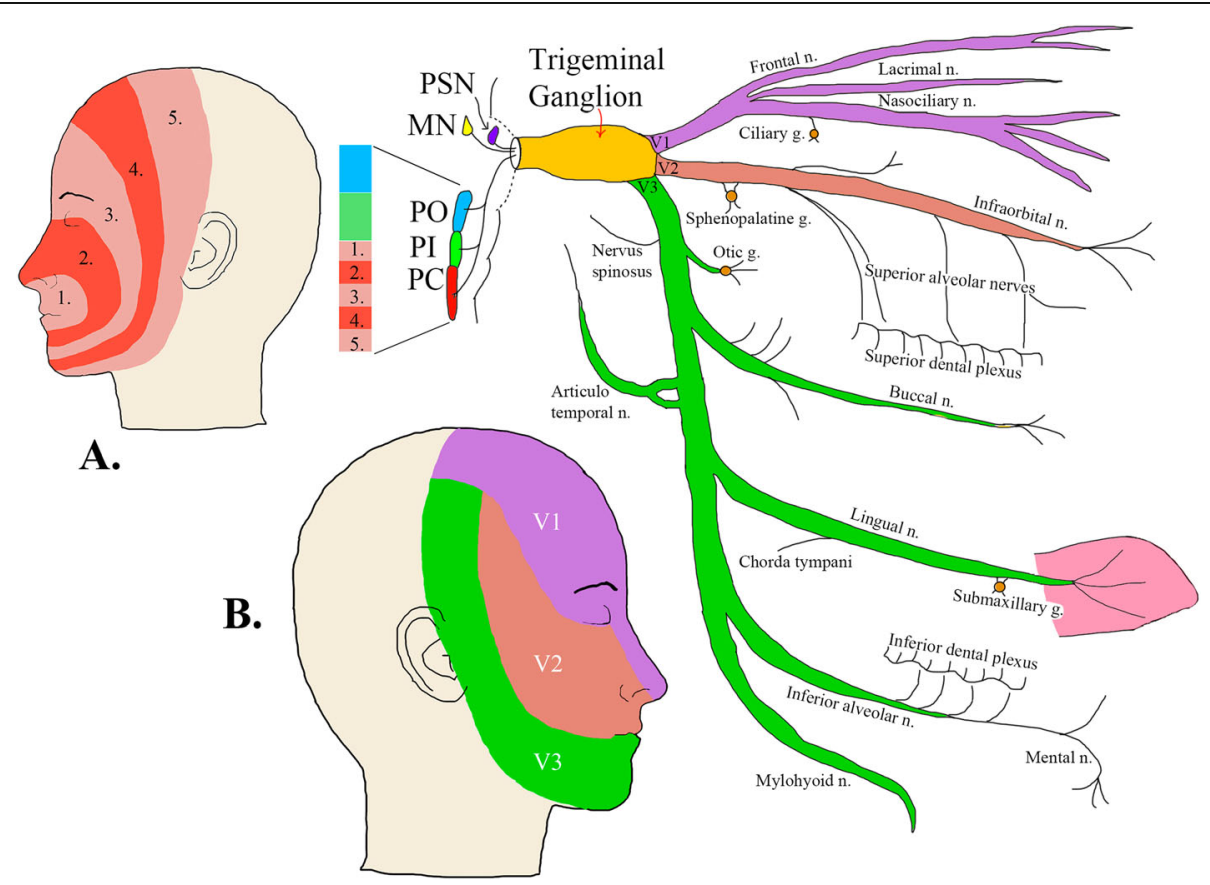

Fig. 1 Schematic of the Trigeminal System. a: The somatotopic distribution of trigeminal nociceptive afferents terminating in the trigeminal nucleus caudalis [1 1]. b: Innervation of facial skin areas and its related three branches (V1, V2 and V3). PSN (Principal sensory nucleus CN V), MN (Mesencephalic nucleus CN V), PA (Spinal nucleus of CN V Pars Oralis), PI (Spinal nucleus of CN V Pars Interpolaris), PC (Spinal nucleus of CN V Pars Caudalis). N. = Nerve. G. = Ganglion 


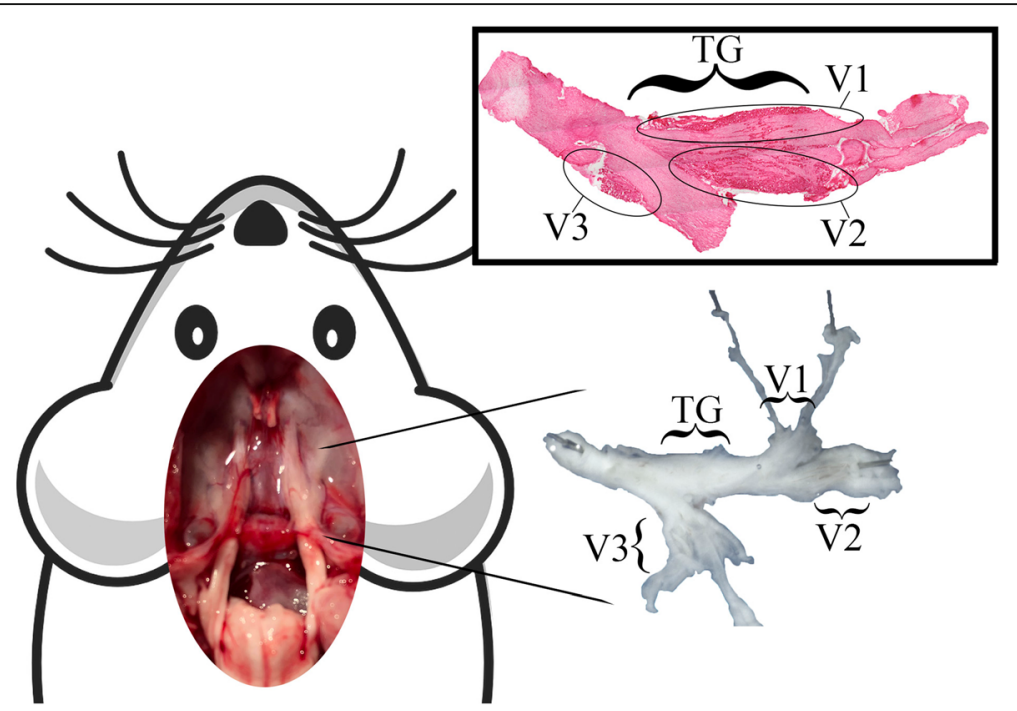

Fig. 2 Left: Superior perspective of a dissected male rat displaying both Meckel's caves containing the trigeminal ganglion (TG). Right: TG and parts of its main branches. Insert: Hematoxylin-eosin staining of rat TG displaying neuron (darker areas) locations and their approximate branch affiliation

to activate superior order sensory neurons inhabiting the TCC which in turn progress the signal to the thalamus and finally cortex.

Interestingly, in an experimental rat study [18], injection of a retrograde tracer in various facial regions could be traced to specific neuron clusters in the TG. The injections were made into regions correlating to the V1 (eyebrow or directly on the eye), V2 (whisker pad) and V3 (temporomandibular joint capsule). When examined, the tracer could be located in TG neuron somas revealing an organisation of the ganglion and a potential origin for each branch (Fig. 2) [18, 19].

The pseudo-unipolar neurons of the TG are implicated in a variety of sensory and nociceptive stimuli, in the craniofacial region, including mechanical, chemical and thermal inputs $[20,21]$. In the TG, small neurons process the action potentials of peripheral noxious stimuli carried by afferent $\mathrm{C}$ - (unmyelinated) and A $\delta$-fibres (thinly myelinated), which are believed to convey the nociception of headache $[14,21]$. The larger diameter, myelinated fibres are, on the other hand, mainly responsible for tactile stimulation processing [22] and also known as low-threshold mechanosensitive afferent $A \beta$ fibres [23-25] that normally do not mediate pain [23].

Applying microscopy, many morphological features of the TG have been described including: the composition of the neuron-glia unit (NGU), nerve bundles and extracellular matrix with microvessels, nerve fibres, together with occasional mast cells and stromal cells [26] that are all dependent on each other [27]. The NGU consists of one to three neuronal cells enveloped by a discontinuous sheath of satellite glial cells (SGC) [26]. Electron microscopy further shows that Schwann cells comprising the myelin sheath combined with microvessels with endothelial cells and to some extent pericytes. The absence of astrocytes could explain why the TG lacks a proper BBB [14, 21, 26].

The sensory fibres innervating intracranial vessels have their origin in the TG and they store a number of neurotransmitters, with the most prominent being glutamate, and neuropeptides, including dynorphins, Calcitonin Gene-Related Peptide (CGRP), serotonin, amylin, substance $\mathrm{P}$, neurokinin A/B, Pituitary Adenylate CyclaseActivating Polypeptide (PACAP). Receptors for these signalling molecules are expressed on peripheral and central structures, and importantly on the TG neurons themselves [14] (for a more detailed review see [28]). Furthermore, these signalling molecules are pivotal in cellular communication for pain processes (e.g. induction or central/peripheral sensitization), and therefore also in headache perception.

Migraine and cluster headache pain seem to rely on the CGRP pathway in the trigeminovascular system as vastly demonstrated (for a review on the subject see [14, 29]). As the TG is lacking a proper BBB [30], and has a high density of CGRP receptors accessible for antimigraine drugs (e.g triptans and anti-CGRP directed drugs), the TG could represent a common denominator for headache and craniofacial pain processing and a preferential target for treatments.

The SGCs form a cellular layer covering almost all sensory neurons in the TG and similar to the astrocytes of other regions of the nervous system, ensure metabolic support, glutamate regulation and ionic balancing. The 
role of SGCs in neuropathic pain has been shown to be involved in the sensorial malfunctioning leading to "maladaptive" plasticity [31-35] that are responsible for chronification process widely described in common forms of headache (e.g. migraine) [36].

In particular, the regulation of extracellular potassium concentrations and consequently the utilization of ATP by specific ATP-ase pumps seems to be one of the regulator mechanisms of pain attributed to SGCs [32, 37]. Also, SGCs could modulate the purinergic system in the TG through vesicular nucleotide transporters (VNUT) [38]. In fact, all the purinergic receptors are expressed in the TG [39]. Purinergic signalling has two-sided effects in the TG. ATP release and the following purinergic activation, after peripheral noxious perineural stimulation, activate both SGCs and neurons in TG [34, 38]. This contrasts to the breakdown product ADP, which instead leads to trigeminovascular deactivation [40].

\section{Anatomy of the fifth cranial nerve The ophthalmic branch (V1)}

The V1 nerve is the first branch of the trigeminal nerve in rostral-caudal order. From the TG it crosses the sidewall of the cavernous sinus and then passes through the superior orbital fissure into the orbit, where it divides into three terminal branches: the lacrimal nerve, the frontal nerve and the nasociliary nerve. These large branches in turn branch off to form smaller and ultimately terminating sensory nerves (e.g the frontal nerve branches off to form the supratrochlear nerve while the nasociliary nerve branches off to form the infratrochlear nerve and the anterior ethmoidal nerve, the latter further forming external nasal nerves).

The V1 is a sensory nerve that innervates the upper part of the face and the two thirds of the anterior scalp, from the level of the palpebral fissures to the area of the coronal suture [41]. The terminals of the lacrimal and nasociliary branches provide the somatic sensation from the eye structures, so that damage of these nerves impair the corneal reflex. The V1 branch provides both superficial and autonomic sensory innervation to the ciliary body, lacrimal gland, conjunctiva, cornea and iris, albeit they do not originate from the trigeminal nucleus but from the superior cervical ganglion and the sphenopalatine ganglion (SPG). The former provides sympathetic fibres for the dilatator pupillae that run in the nasociliary branch, the latter provides parasympathetic fibres for the lacrimation partially running in the lacrimal branch of V1 $[42,43]$.

Furthermore, V1 supplies intracranial structures sensitive to pain, the superior part of the nasal cavity, medial orbital roof, crista galli, and the dura mater meninges, cerebral arteries in the circle of Willis [44], and, through the tentorial nerve of Arnold, reaching the traverse and straight venous sinuses [45]. Noxious stimuli to the intracranial sensory receptors are transduced predominantly by the ophthalmic branch because the maxillary and mandibular branches, or cervical dorsal root ganglia, provide the innervation of only a limited extent of the meninges [46-50]. This likely explains why the majority of headache present as painful sensation in this territory.

\section{The maxillary branch (V2)}

The V2 nerve is the second branch of the trigeminal nerve. It reaches intracranially the dura of the middle cranial fossa, the upper teeth and the related oral gingiva, the palate and mucous membranes of the maxillary sinuses and nasal cavity [51]. Postganglionic parasympathetic neurons from the SPG (innervated by TG fibres) reach the lacrimal gland trough V2 branches, where they mix with homologous fibres coming from V1. Similarly, sphenopalatine branches supply intramural glands of the nose and the hard palate.

As a sensory nerve, V2 innervates the skin of the lower eyelid, the sides of the nose, nasolabial fold, upper lip and the cheek.

\section{The mandibular branch (V3)}

The V3 nerve is the largest of the three branches of the trigeminal nerve in humans. V3 passes between tensor veli palatini and lateral pterygoid and gives off a meningeal branch (nervus spinosus, so called because it passes through the foramen spinosum) and the nerve to medial pterygoid from its medial side. The continuation of the mandibular nerve then splits into an anterior and a posterior trunk. The anterior trunk gives off branches to three major muscles of mastication and a buccal branch, which provides sensory innervation to the cheek. The posterior division gives off three main sensory branches, the auriculotemporal, lingual and inferior alveolar nerves and motor fibres to supply mylohyoid and the anterior belly of the digastric muscle [52].

The V3 branch innervates a territory of skin covering the posterior part of the temporal region, the anterior part of the earlobe, the anterior and superior walls of the external ear canal, the lower lip and the chin. Its mucosal territory covers the anterior two-thirds of the tongue, the medial aspect of the cheek and the floor of the oral cavity, the gingiva, and the mandibular alveoli and teeth. As previously mentioned, the V3 branch also carries trigeminal motor fibres that innervate the masticatory muscles (masseter, temporal, internal and external pterygoid, mylohyoid, anterior body of the digastric and the tensor palati) controlling biting and chewing mechanisms [53]. 


\section{The Trigeminocervical complex (TCC)}

The first order sensory neurons of the TG project centrally to the trigeminocervical complex (TCC) in the brainstem. The TCC includes the second order neurons of the trigeminal sensory pathway inhabiting the trigeminal nucleus caudalis (TNC) and $\mathrm{C} 1$ and $\mathrm{C} 2$ segments of the cervical spinal region [54]. While historically considered as two separate entities, recently the trigeminal system has been considered both as a morphological [5] and a functional ensemble with first cervical roots [55]. The part of the TNC dedicated to pain perception is the lower part, the Pars Caudalis (PC), while rostral parts are mainly deputed to tactile perception. This pain specific part of the TNC extends from $\mathrm{C} 2$ or $\mathrm{C} 3$ rostrally to the level of the obex. The TNC has many cytoarchitectural similarities with the posterior horn. For this reason, it has been termed "medullary posterior horn" and has been divided into layers that correspond to Rexed spinal cord laminae [56]. The TNC and the posterior horn also show homology in the distribution of neurotransmitters; substance P and CGRP are localized in nociceptive Cfibres that terminate in both of these areas [56]. The most superior area of the TNC is the inferior medulla and the most inferior area is the upper cervical spinal cord [57]. The spinal trigeminal nucleus is a sensory tract located in the lateral medulla of the brain stem and descends to the caudal end of the medulla and into the spinal cord (as far as the third or fourth cervical level), where it becomes continuous with Lissauer's tract [58] and takes sensory information from different cranial nerves, including the trigeminal nerve and its branches [54].

The innervation of the face forms a somatotopic map in the TNC, which is stretched and distorted into the proportions of the $\mathrm{PC}$ of the spinal trigeminal nucleus (Fig. 1a). The area of lips and perioral area constitute the outermost layer of the onion meaning that they lie within the most superior area of the TNC [57]. The next innermost layer lies inferiorly within $\mathrm{PC}$ and comprises the projections of nose, eyes, and outer oral areas. The V1 branch travels in the most ventral part of the spinal tract and extends caudally. The V2 branch lies in the most dorsal part of the trigeminal nucleus caudalis and terminates in the most rostral level [54]. In the lowest part, there are areas reserved to cheeks and forehead; then the vertical area of the ears; and finally the partial sensory innervation of the external ears (from cranial nerves VII, IX, and X) [57]. This pattern of termination may account for the onion skin pattern of facial sensory loss with intramedullary lesions [54]. The TNC that runs medial to the spinal trigeminal tract, also has an onion skin somatotopy, and divides into three different cytoarchitectural regions: Pars Oralis (PO), Pars Interpolaris (PI) and PC. PO is the most superior nucleus, running from the pons to the mid-medulla. PI is the middle nucleus, spanning in the mid-medulla. PC is the most inferior nucleus from the lower medulla to the upper cervical spinal cord. Its inferior extent is variably listed from C2 to C4 [57].

Pradier and McCormick reported in their study, based on electrophysiological characteristics of neurons of the $\mathrm{TNC}$, that there are five main groups of neurons, including; tonic, phasic, delayed, $\mathrm{H}$-current and tonic-phasic neurons, groups that exhibit distinct intrinsic properties and share some similarity with groups identified in the spinal dorsal horn [59]. The primary function of the TNC is to carry information on temperature, deep or crude touch (PO and PI), and pain from the portion of the face (PC) [54]. Afferents from the TNC terminate at third-order neurons inhabiting the thalamus (mainly posterior and ventral posteromedial thalamic nuclei) [58, 60].

In addition to this major pathway, TCC is also responsible for conveying sensory and nociceptive signalling from the meninges and craniovascular structures to several higher order relays. There are numerous direct ascending connections within the medulla (e.g. medullary pontine nuclei including the rostral ventromedial medulla), brainstem (e.g. nucleus raphe magnus, parabrachial nucleus and locus coeruleus), midbrain nuclei (e.g. ventrolateral periaqueductal gray and cuneiform nucleus), and diencephalon (e.g. hypothalamus and thalamus) $[54,58]$.

Activation of these structures are believed to contribute to the perception of pain during migraine, and also to autonomic, endocrine, cognitive and affective symptoms that last throughout the migraine episode [54]. Furthermore, the second order neurons receive inputs from the occipital nerve. This convergence may have treatment implications for some primary headache conditions as well as referred pain.

\section{Trigeminohypothalamic tract and the parabrachial-limbic tract}

Although a detailed description of these relay-functions lies outside the purpose of the present review (for details see $[61,62])$, we will briefly discuss the trigeminohypothalamic tract and the parabrachial-limbic tract.

The trigeminohypothalamic tract originates from specific nociceptive, multimodal intensity-coding wide dynamic range (fundamental for pain "gating effects") and non-nociceptive neurons, albeit about the $80 \%$ of its fibres are axons from nociceptive neurons [61]. The trigeminohypothalamic tract ascends contralaterally in the brainstem but about half of the fibres present a decussation in the lateral hypothalamus, reaching both lateral and medial structures of hypothalamus (e.g. prefornical, suprachiamatic, supraoptic nuclei). While non- 
nociceptive information are transmitted only by direct pathway, nociception is carried both directly and indirectly (i.e. trigeminoreticular tract) to hypothalamus, suggesting a more resistant mechanism to pathological noxae for nociception [62]. Receiver areas of the hypothalamus are those regulating homeostasis and integrating pain with visceral afferent input [63].

The trigeminoparabrachial tract is a polysynaptic pathway connecting $\mathrm{CN} \mathrm{V}$ to the limbic system, with direct tracts ending in the amygdala, lenticular nucleus, nucleus accumbens and it is thought to exert, among other functions, the transmission of visceral pain and the emotional value of pain sensations $[62,64]$. The parabrachial nucleus, in fact, contains a large share of neurons expressing both CGRP and PACAP, especially in its lateral portion, which is the one activated by painful stimulation [65-67]. The transmission of CGRP is thought to reach directly the limbic system, where it can mediate aversive behaviour or freezing, as demonstrated in mice with injection of CGRP into the insula region [68].

\section{The trigeminal system in primary headache conditions}

In the headaches most commonly seen in specialized units (e.g. migraine, TTH, trigeminal autonomic cephalalgias (TACs)) the pain generating mechanism resides in the complex relationship between trigeminal system and intracranial structures sensible to pain (mostly vessels and meninges). For this reason, the functional ensemble of the trigeminovascular system is quite relevant for the understanding of head and facial pain pathophysiology. We will now continue to describe some of the more notorious headache and facial pain diagnoses.

Other less common primary headaches, which are not explored in this article, that also might affect the trigeminal area are: primary stabbing headache (head pain occurs as a single stab or as a series of stabs), nummular headache (characterized by small circumscribed areas of continuous pain on the head), cold-stimulus headache (a direct result of the rapid cooling and rewarming of the capillaries in the sinuses leading), and external pressure headache (external pressure on pain receptors or pain fibres) [1].

\section{Tension type headache}

As previously mentioned, TTH is the most prevalent primary headache $[23,69]$. The definition of TTH can be defined as a mild to moderate bilateral headache with a steady non-pulsating pain which is unaffected by movement and lasting $30 \mathrm{~min}$ to 7 days [70]. Furthermore, TTH is not associated with nausea or vomiting and can manifest with either photophobia or phonophobia. The pathophysiological mechanism of TTH is not yet completely clear and most likely multifactorially determined. Central sensitization of the trigeminal nerve seems to play an important role, especially in patients with chronic TTH.

Patients with episodic and chronic TTH have a considerably increased tenderness to palpation of pericranial myofascial tissues [71]. This increased tenderness originates from muscles, fascia and tendons throughout the pericranial region, probably due to sensitization of $A \delta$ and C-fibres [71]. After a strong peripheral nociceptive stimulus from pericranial myofascial tissues central sensitization can occur; ineffective synapses can change to effective contacts of low threshold mechanosensitive afferent nerves and superficial second order nociceptive neurons in the trigeminal nucleus, which usually receive input from high threshold mechanoreceptors [25]. This central sensitization may make innoxious stimuli more aggravating to the pain modulating systems, resulting in allodynia and hyperalgesia [23, 71].

\section{Migraine}

In migraine, intracranial vasculature is innervated by trigeminal fibres (see above for details). Intracranial sensory receptors cover the rich plexus of meningeal perivascular nerves of pial and dural blood vessels. Currently, this classical vascular theory, naming vasodilation as the migraine pain generator, seems less reliable compared to a theory focusing on central sensitization, where activation of neuronal receptors is pivotal as origin of migraine pain. The current paradigm is supported by evidence of hypothalamic activation [72] and the view of vasodilation as an epiphenomenon rather than a causation of pain [73-75]. Nevertheless, the current review does not focus on the origin of the migraine attack, but the origin of the perceived pain, which most likely resides in the TG and the associated sensory fibers.

Whichever the trigger, the repeated experimental activation of the TG leads to release of vasoactive neuropeptides, such as substance P, CGRP [76] and PACAP [77]. CGRP and several other substances have been shown to evoke headaches after intravenous administration both in healthy subjects and migraineurs, and to trigger a delayed migraine-like attack in the latter group [78]. The release of vasoactive neuropeptides from the peripheral terminals of trigeminal nerve may result in neurogenic vasodilatation, plasma extravasation and trigeminal nerve sensitization, at least in rodents. It remains questionable whether the throbbing quality of migraine pain and aggravation by head movements or routine physical activity are expression of peripheral [79] or central sensitization process [46].

In addition to the importance of the neuropeptide signalling, some of the transient receptor potential (TRP) channels, which are identified in trigeminal ganglion, vagal ganglia and in dorsal root ganglia could play an 
important role. Those superfamily of receptors expressed in the trigeminal ganglion are mainly TRP vanilloid 1 (TRPV1) [80] and TRP ankyrin 1 (TRPA1) channels which might be involved not only in pain initiations but also as future treatment-targets in migraine [81]. TRPM8, which mediates the cold sensation has also been linked to migraine pathophysiology by genome wide association studies (GWAS), especially in the northern population through a mechanism of evolutionary selection $[82,83]$.

\section{Chronification, sensitization and habituation}

Migraine is a progressive disorder and can transform from an episodic state to a chronic state. According to ICHD-3 [1], chronic migraine (CM) is defined as the presence of headache for 15 or more days/month for at least 3 months with migraine associated symptoms. A well-accepted mechanism driving the progression from episodic to $\mathrm{CM}$ is the peripheral sensitization of the primary afferent TG neurons, which leads to central sensitization of TNC second-order neurons and ultimately to central sensitization of third order neurons in the thalamus $[46,84]$.

In a first phase of activity-dependent central sensitization, the TNC neurons, under repetitive, persistent nociceptive stimuli from the TG, become sensitized and produce exaggerated and prolonged responses to lower threshold stimuli. Over time, a neuroplastic adaptation in medullary and cortical pain areas causes a shift in the pain modulatory system creating a new threshold and favouring a net pain facilitation rather than pain alleviation. This shift to activity-independent central sensitization plays a crucial role in the conversion to CM $[85,86]$.

Based on experiments by Burstein et al, it is hypothesized that cutaneous allodynia serves as a clinical indicator of migraine chronification. Particularly, the development of cutaneous allodynia in the head indicates that central sensitization affects mostly neurons in TNC, while the whole-body allodynia is mediated by the central sensitization of third-order neurons, suggesting a thalamic involvement [87]. On a molecular level, the interictal levels of trigeminal CGRP are significantly elevated in patients with $\mathrm{CM}$ when compared to those with episodic migraine [88]. Interestingly, recent reviews proposed an interaction between CGRP and inflammation [89]. This process finally leads to increased production of pro-inflammatory mediators, which sensitize TG neurons $[76,90]$. One example is the activation of TG neurons by peripheral (dural) inflammation [91], which mimics some of the features of CM.

NMDA-receptors, nitric oxide, and endogenous substances such as serotonin, bradykinin, substance $\mathrm{P}$ and CGRP are involved in the development of this central sensitization of the trigeminal nucleus and spinal dorsal nucleus $[23,24,92]$. Central sensitization, e.g. of the trigeminal nucleus will induce an increased pain transmission signal to the thalamus, limbic system and sensory cortex. The descending pathways of the rostral ventromedial medulla will facilitate the sensitized nociceptive second order neurons of the trigeminal nerve [71]. Although the majority of studies focused on migraine, the chronification mechanism of TTH seems to be not so different [71].

Sensitization has received the most interest in primary headaches and pathologies of the fifth cranial nerve. However, Groves and Thompson already in 1970's proposed a "dual-process" theory [93]. The basis of this theory was based on the balance between depression (habituation) and facilitation (sensitization). Unlike sensitization, the neural mechanisms underlying habituation remain poorly understood [94].

Abnormal habituation patterns in migraineurs still lacks a definitive consensual interpretation. Nevertheless, there are some suggestions in the literature that central habituation could play a role in cluster headache $(\mathrm{CH})$ and episodic migraine. For $\mathrm{CH}$ a habituation deficit of brainstem reflex responses has been observed [95]. Regarding episodic migraine, it was found that controls had a habituation response to repetitive sensory stimulation in contrast to migraine subjects. Therefore, it seems that amplified information processing from spinal trigeminal relay nuclei is linked to an impaired habituation response in migraineurs [96]. The cellular/physiological origin of these responses remains to be determined.

\section{Medication overuse headache}

Medication overuse headache $(\mathrm{MOH})$ is considered a secondary headache, with significant implications to primary headache sufferers. $\mathrm{MOH}$ is defined as a preexisting headache (occurring at least 15 days/month) worsening due to regular overuse of medication (used > 10-15 days/month depending on the medication) for treatment of an acute or symptomatic headache for more than 3 months [97]. Medication overuse is the major risk factor for chronification in all primary headache forms, although the $80 \%$ of $\mathrm{MOH}$ patients have migraine as original primary headache, a smaller part TTH, and rarely post-traumatic headache [98].

Similarly to $\mathrm{CM}$, in an $\mathrm{MOH}$ rat-model, persistent triptan exposure produced cutaneous allodynia and central upregulation of CGRP and neuronal nitric oxide synthase (nNOS) [99, 100]. Moreover, reduced serotonergic transmission seems to be involved in $\mathrm{MOH}$ development [101], possibly through a facilitation of the sensitization process via a maladaptive plasticity [98]. In humans, common neurophysiological investigation of central sensitization shows an abnormal cortical 
response to repetitive sensory stimuli, with an increased response amplitude after low numbers of stimuli [102] and a lacking habituation (which is instead normal in chronic migraineurs without $\mathrm{MOH}$ ) [102], suggesting an altered plasticity.

A recent neurophysiological study investigating the serotonergic tone, found a low baseline serotonergic tone in chronic migraineurs with $\mathrm{MOH}$, but it recovers after a week following anaesthetic block of the greater occipital nerve. Moreover, the size of the recover positively correlated with the clinical benefit after a month [103].

\section{TACs: cluster headache, SUNCT and SUNA}

Trigeminal autonomic cephalalgias (TACs) are rare, but highly disabling primary headache disorders. The most common of the TACs is $\mathrm{CH}$, known for its severely painful symptoms. Other subgroups of TACs are hemicrania continua $(\mathrm{HC})$, paroxysmal hemicrania $(\mathrm{PH})$, short-lasting unilateral neuralgiform headache with conjunctival injection and tearing (SUNCT) and shortlasting unilateral neuralgiform headache with cranial autonomic symptoms (SUNA).

The unifying pathophysiological mechanism for TACs is the role of the trigeminal autonomic reflex with parasympathetic activation and clinical presentation with strictly unilateral pain in the distribution of the trigeminal nerve and cranial autonomic features ipsilateral to the pain. Distribution of maximal pain in TACs is at the first branch of trigeminal nerve (V1) $>$ upper cervical root $(\mathrm{C} 2)>$ second branch $(\mathrm{V} 2)>$ third branch $(\mathrm{V} 3)$ [104].

Evidence for the peripheral mechanisms in $\mathrm{CH}$ include increased plasma levels of CGRP, PACAP [105] and vasoactive intestinal peptide (VIP) during acute cluster attack and even interictally [106]. Recently, a clinical study with a monoclonal antibody against CGRP was found positive in prevention of episodic $\mathrm{CH}$ [107]. Furthermore the SPG has connections to the trigeminovascular system, superior salivatory nucleus (SSN) and posterior hypothalamus: all areas that have an important role in the generation of $\mathrm{CH}$ attacks [108].

The last decade has brought more insight into pathogenesis of TACs, but still it is controversial whether the pain in TACs has a peripheral or central origin. Studies using animal models have shown that activation of trigeminal nerve may lead to activation of parasympathetic efferents, producing autonomic symptoms such as lacrimation, rhinorrhea and nasal congestion via the trigeminal-autonomic reflex. The origin of the cells for the parasympathetic autonomic vasodilator pathway is in the pontine SSN. The efferent projection is predominantly through the greater petrosal nerve, a branch of the facial nerve, and its projection through the SPG.
All primary headaches can be presented with autonomic symptoms to some degree, through reflex activation of the cranial autonomic outflow [109, 110]. A parasympathetic outflow activation probably results from stimulation of trigeminal afferents. In this trigeminal autonomic reflex, SPG may have a considerable role: in clinical studies, stimulation of SPG reduces intensity and frequency of $\mathrm{CH}$ pain [111]. The cyclical recurrence of the disorder (circadian and circannual rhythmicity), behavioural features, such agitation and restlessness, during acute cluster attacks, as well recently study on preictal and postictal symptoms in $\mathrm{CH}$, led to theory of the key role of hypothalamus.

Genetics and neuroimaging studies has implicated that the brain and particularly the hypothalamus as a generator of TACs $[109,112]$. Animal studies have shown that there are direct hypothalamic-trigeminal connections (trigeminohypothalamic tract), and bilateral descending hypothalamic projections to the spinal trigeminal nucleus [61]. Moreover, neuromodulation such as deep brain stimulation of posterior hypothalamus, occipital nerve stimulation, SPG stimulation has shown benefit to resistant chronic $\mathrm{CH}$. Furthermore, cutting the trigeminal nerve root or ablative methods of TG does not resolve the pain in TACs [113].

In SUNCT and SUNA there are some similarities with trigeminal neuralgia (TN) that imply the involvement of neuropathic pain mechanisms, for example, the shortlasting unilateral attacks of pain, the cutaneous triggering and the response to antiepileptic medications [114]. TN will be covered below as we move on to conditions more plausibly linked to specific trigeminal nerve branches.

\section{Other painful conditionals of the trigeminal nerve branches \\ The ophthalmic branch}

Trigeminal Neuralgia (TN) is defined according to ICHD-3 criteria, as "recurrent unilateral brief electric shock-like pains, abrupt in onset and termination, limited to the distribution of one or more divisions of the trigeminal nerve and triggered by innocuous stimuli" [1]. The International Association for the Study of Pain (IASP) defines TN as "sudden, usually unilateral, severe, brief, stabbing, recurrent episodes of pain in the distribution of one or more branches of the trigeminal nerve" [115]. TN is a challenging syndrome and a common cause of head and facial pain, and usually along the distribution of the second or the third branch [116], therefore $\mathrm{TN}$ is covered in more detail below, as only a minority of cases of TN involves the first division of the trigeminal nerve.

Among the few secondary causes of headache in V1 are Tolosa-Hunt syndrome, orbital cellulitis, idiopathic 
intracranial hypertension and herpetic neuralgia. Damage to V1 can cause complex syndromes, as paratrigeminal oculosympathetic syndrome (Raeder's syndrome) and recurrent painful ophthalmoplegic neuropathy (RPON) [117]. Raeder's syndrome is a constant, unilateral pain caused by a disorder in the middle cranial fossa or of the carotid artery. RPON is an uncommon disorder with repeated attacks of paresis of one or more ocular cranial nerves (commonly the 3rd), with ipsilateral headaches [1]. The headache features are similar to typical migraine with frequent accompanying symptoms, such as nausea, vomiting photophobia and phonophobia. RPON is a diagnosis of exclusion. The differential diagnosis comprises all types of inflammatory or spaceoccupying lesions in the parasellar region and in the orbita [118].

One neuralgia that is linked to the V1 branch, is supraorbital neuralgia, characterized by persistent pain over the supraorbital region and medial region forehead [119]. It may be differentiated from supratrochlear neuralgia based on the topography of the pain, which can be confirmed with anaesthetic blockade [120]. Lacrimal neuralgia, is pain localized to the orbital and periorbital area, and was first described in 2013 [121]. All of these headaches are linked to V1, but little is known about their molecular pathophysiology. This is also the case for trochleodynia which is a spectrum of disorders characterized by pain arising from the trochlear region [122] and idiopathic ophthalmodynia [123] which is linked to pain in the eyeball.

Pain due to a cavernous sinus lesion, which is usually causing total ophthalmoplegia and being accompanied by a fixed, dilated pupil [124] or compression on the structures passing through the superior orbital fissure [125] can due to the anatomy also compromise the V1 branch. Furthermore, many cranio-cervical structures might present with facial pain and it is important always to be sure that the pain is not better accounted for by another diagnosis [1].

\section{The maxillary branch}

Pain conditions linked to the V2 branch vary from mostly frequent $\mathrm{TN}$ to facial presentations of primary headaches. The diagnosis of TN is clinical and depends fundamentally on the description by the patient and characterization of pain [126]. TN is typically a unilateral condition, slightly, but significantly more frequent, on the right side [127]. Contrary to secondary forms, classical TN includes idiopathic cases as well as those caused by neurovascular compression, demonstrated by magnetic resonance imaging (MRI) or surgery, determining morphological changes to the trigeminal nerve root that represents about the $50 \%$ of cases. The exact extent of this neurovascular conflict needed to induce $\mathrm{TN}$ is still debated [128].

Classical TN may be purely paroxysmal, without concomitant continuous pain, or it may be with persistent background pain.

For TN, patients may describe a trigger point that elicits pain when touched: this could be interpreted as a manifestation of an erratic hyperactive functioning of the nerve. Furthermore, central causes have been proposed, even if it is difficult to determine which of the these changes are cause and effect: volume reduction in somatosensory cortex, thalamus and other subcortical areas has been observed [129], as well as functional connectivity alterations were described in sensory trigeminal pathways [130]. Sometimes trigeminal nerve atrophy can be demonstrated in patients with TN by high-resolution imaging and it is significantly correlated with the severity of neurovascular compression [131].

Another important cause of facial pain in the V2 territory, which has been considered "the atypical counterpart to trigeminal neuralgia" [132], is the persistent idiopathic facial pain (PIFP), previously termed atypical facial pain or atypical odontalgia when occurring in the oral cavity. PIFP is defined as a continuous facial pain, typically localized in a circumscribed area of the face, which is generally not accompanied by any neurological or other lesion identified by clinical examination or clinical investigations [132]. This facial pain, which occurs daily and persists throughout the day, is generally described as deep, poorly localized, and is not associated with sensory loss or other neurological deficits, which differentiates it from a pure neuropathic process. The pathophysiology is not fully elucidated and possibly it relies on a combination of neuropathic pain, central sensitization, and local inflammation [132-134].

This complex pathophysiology is reflected by the difficulty in treating PIFP successfully, and the concept that different types of interventions are needed [135]. While the large majority of case are idiopathic with investigations including X-ray of the face and jaws or cranial computed tomography (CT) or MRI not demonstrating any relevant abnormality, a part of PIFP-like disorders can be secondary to dental or oral conditions [136-138].

Lastly, neuralgia of the infraorbital nerve (numb cheek syndrome) is an unusual cause of facial pain, most often associated with the V2 branch [139]. The pain can be characterized by constant discomfort, often in the form of stabbing pain, often accompanied with hypersensitivity to palpation in the infraorbital notch [140], and can be linked to an underlying cancer [141].

\section{The mandibular branch}

A trigeminal nerve injury that mainly affects its V3 branch is characterized by acute paroxysmal painful 
episodes $[142,143]$ with a sudden onset that may involve all the aforementioned structures [144]. The typical associated symptoms are PIFP or burning mouth like syndrome (BMLS) [145]. While PIFP can affects either V2 or V3, with a preference for the former, BMLS is defined as a multifactorial chronic pain condition characterized by a burning or stinging sensation, often accompanied by xerostomia and preferably located on the tongue or, in a lesser extent, other specific areas of the mouth, in a clinically healthy oral mucosa [146]. The epidemiology varies from $0.01 \%$ to $40 \%$ according the studies, generally observed in middle-aged patients and postmenopausal women [147, 148].

No definitive aetiology has been established for burning mouth syndrome, an intramural burning sensation for which no medical or dental cause can be found: both central and peripheral nervous systems seem to be involved and some studies suggested a trigeminal small fibre sensory neuropathy in innervation territory of maxillary nerve [149]. The diagnosis is generally reached after a series of tests, including neurophysiological evaluation and peripheral lingual nerve anaesthetic block, allowing the distinction between peripheral and central forms (for a review, see [150]). Therapeutic options remain however low, with only topical or systemic lowdose clonazepam as a valuable treatment [151, 152]. Topical capsaicin or saliva substitute are second line options in peripheral forms, while amitriptyline or gabapentin are considered in central form [150].

One of the most "dangerous" neuralgias is the "Numb chin syndrome" which can occur from a lesion anywhere along the course of the trigeminal nerve. Typically it represents loss of the terminal and sensory branch of the mandibular branch and is often linked to cancer, such as metastatic tumours [153].

Finally, temporomandibular disorders are also linked to the V3 branch [154]. TN can be differentiated from temporomandibular joint dysfunction by the acute, piercing, and stabbing nature of neuralgic pain occurring at a single facial location, spreading along the course of the nerve on one side, leading to differences in the character and intensity of the pain [155].

\section{Treatments targeting the trigeminal nerve}

\section{Acute treatments}

Although many new therapeutic targets are under investigation [156], the most frequently used acute treatment for headaches are non-specific drugs, such as NSAIDs.

Cyclooxygenase 1 and 2 (COX-1, COX-2) inhibitors have peripheral effect on prostaglandin synthesis involved in inflammatory processes. Acetylsalicylic acid is found to have additional inhibitory effect on the central trigeminal neurons after sagittal sinus stimulation [157]. Ketorolac (a nonselective COX-inhibitor) was found to prevent sensitization at the trigeminal nucleus neurons [158]. COX-2 inhibitor piroxicam showed good effect in $\mathrm{PH}$ and celecoxib in $\mathrm{HC}$ [159].

It has been shown that some TACs (e.g. PH) respond well to indomethacin. In a case study, the patient became pain-free overnight after the use of indomethacin after 12 years of failed treatments [160]. Indomethacin is a COX-inhibitor that inhibits evoked firing in the TCC in animal models [110]. Furthermore, indomethacin exerts an effect on IL-1 $\beta$ induced prostaglandin $E$ synthesis via COX-2 in cultured rat trigeminal cells. Consequently to the blockage of prostaglandin $\mathrm{E}$ release, the release of CGRP was inhibited [161, 162]. According to studies, indomethacin has higher odds of responders and complete responders than any other treatment option in $\mathrm{HC}$ and $\mathrm{PH}$ [159]. On the other hand, indomethacin can also inhibit NO-induced vasodilatation. Contrary to NOinduced $\mathrm{CH}$-like and migraine-like headache that start after a certain delay from $\mathrm{NO}$ administration, NOinduced $\mathrm{PH}$ symptoms begin immediately after the administration, and this can be the reason behind the different effectiveness of indomethacin [163].

Furthermore, there are a subcategory of headaches that seem to response well to indomethacin, so called "Indomethacin-responsive headaches". These are sexual headache, trocheodynia, Valsalva-induced headache, primary stabbing headache, hypnic headache and primary exertion headache (also called exercise headache) [164]. This could be linked to inhibitory effect of indomethacin on trigeminal nociceptive firing and the trigeminoautonomic activation, which has been shown in animals by Akerman et al. [165].

Ergotamine and dihydroergotamine were the first specific acute antimigraine drugs in use for several decades [166]. Ergot alkaloids are non-specific $5-\mathrm{HT}_{1}$ receptor agonists that also bind $\alpha$-adrenoceptors and dopamine receptors. Therapeutic effect of these drugs likely originates from their agonist properties at $5-\mathrm{HT}_{1 \mathrm{~B}}$ and $5-\mathrm{HT}_{1 \mathrm{D}}$ receptors that lead to trigeminal inhibition by, for example, reducing CGRP release $[167,168]$. Other previously proposed antimigraine mechanisms include constriction of large capacitance arteries, closure of arteriovenous anastomoses, inhibition of neurogenic inflammation, and blockade of transmission in the TNC [169].

Triptans have been studied in the context of headaches for decades. They are potent $5-\mathrm{HT}_{1 \mathrm{~B} / 1 \mathrm{D}}$ receptor agonists, a majority of them are also $5 \mathrm{HT}_{1 \mathrm{~F}}$ receptor agonists [170]. There is evidence that triptans exert their clinical effect peripherally by binding to $5-\mathrm{HT}_{1 \mathrm{~B}}$ receptors, resulting in slight vasoconstrictive properties as well as blocking CGRP release and centrally by blocking trigeminal transmission through binding at $5-\mathrm{HT}_{1 \mathrm{D}}$ receptors in the trigeminal nuclei of the brainstem [171]. 
In addition to being important in treating migraine, triptans (especially subcutaneous sumatriptan) are considered the most effective treatment in cluster headaches [172]. Subcutaneous sumatriptan was reported to decrease pain significantly also in TN [173]. In clinical practice, triptans are preferred to ergotamine derivatives, because they are at least as potent, with better tolerability and fewer side effects [158].

Ditans are selective $5-\mathrm{HT}_{1 \mathrm{~F}}$ receptor agonists that were developed in hope to increase the effectiveness and to lower the risk of cardiovascular side effects of triptans. $5-\mathrm{HT}_{1 \mathrm{~F}}$ receptors are located in both peripheral and central sensory trigeminal neurons, and their activation is found to hyperpolarize nerve terminals inhibiting trigeminal impulses [174], inhibit the CGRP-mediated vasodilation in vivo, modulate the pain perception pathway and prevents CGRP release [170, 175]. Lasmiditan is the only compound of this drug class that has been evaluated in Phase III clinical trials and approved by the FDA [176]. It penetrates the BBB and could thus exert effects centrally, in addition to the trigeminovascular system [174].

Gepants antagonize the CGRP receptor in trigeminal system. These drugs were promising in trials but were discontinued due to low oral bioavailability (olcegepant) and unexpected hepatotoxicity (telcagepant) [177]. However, ubrogepant and rimegepant tablets have both recently received FDA approval (23rd December 2019 and 27th February 2020) for acute treatment of migraine in adults [178].

Sodium channel blockers, such as lidocaine, blocks sodium channels in a frequency-dependent and voltagedependent manner. The nerve block with lidocaine stops the nociceptive firing and the neuronal hyperexcitability in first order neurons reducing peripheral sensitivity [179]. Intranasal lidocaine administered ipsilaterally to the pain to anaesthetize the SPG, which is responsible for the autonomic symptoms associated to TACs or other headaches via the trigemino-autonomic reflex [180]. Intranasal lidocaine is considered a second line treatment for $\mathrm{CH}$ [181]. The most effective treatment of SUNCT/SUNA acute attacks is considered to be intravenous lidocaine, subcutaneous treatment also can be used [159]. Furthermore, TN studies have shown that lidocaine, rubbed onto the trigger zone of the oral mucosa, provided a few hours of pain relief [173].

Some voltage-sensitive sodium channel blockers, such as lamotrigine or amides (carbamazepine, oxcarbazepine, eslicarbazepine), are often the first line treatment for some painful conditions affecting the trigeminal nerve, and most likely they act by stabilizing neural membranes and inhibit the release of neurotransmitters [182]. In a Cochrane review (from 2013) it was concluded that there was no reduced headache frequency from carisbamate, clonazepam, lamotrigine, oxcarbazepine, pregabalin, or vigabatrin [183]. However, carbamazepine has shown some effect in familial hemiplegic migraine [184]. Further studies are needed to determine the efficacy of the newer drugs [185].

High-flow oxygen is considered a first line treatment for $\mathrm{CH}[172,181]$. The mechanism of action of oxygen in now thought to be related not to its vasoconstrictor effect, but rather to the inhibition of neuronal activation in the TNC [186]. Oxygen is also thought to normalize the CGRP levels and thus reduce the activity in the trigeminovascular system [106].

\section{Prophylactic treatments}

CGRP released from trigeminal terminals results in vasodilation via CGRP receptors on the smooth muscle cells of meningeal and cerebral blood vessels [187] and activation of A $\delta$-fibres, with the possibility of inducing sensitization [188]. Although antibodies can theoretically target CGRP or its receptors in the brain regions, the BBB permeability is low $[189,190]$. Therefore their therapeutic action may be entirely peripheral and likely affecting targets within the trigeminovascular system [191, 192].

Monoclonal antibodies acting on CGRP pathway, with indications for migraine prevention, have been developed in recent years: one targeting the CGRP receptor (erenumab) and three targeting the CGRP peptide (eptinezumab, fremanezumab and galcanezumab) [193]. Fremanezumab inhibits activation of central trigeminovascular neurons with input from the intracranial dura, but not the facial skin or cornea [194] providing evidence that antibodies against CGRP can inhibit trigeminal neuron activation. However, their site of action along the trigeminal pathway remains uncertain, though recently, axon-axon signalling at the node of Ranvier between $\mathrm{C}$ - and $\mathrm{A} \delta$-fibres was suggested as a plausible site of action [167]. A role for the trigeminal nerve in $\mathrm{CH}$ and $\mathrm{PH}$ is indicated by the increased concentrations of CGRP in the ipsilateral jugular vein during attacks [106, 195]. Galcanezumab was recently reported to reduce the frequency of episodic $\mathrm{CH}$ attacks [107].

Onabotulinumtoxin A, beta blockers (e.g propranolol), tricyclic antidepressants (e.g amitriptyline), anticonvulsants (e.g topiramate) and calcium channel blockers (e.g flunarizine) continue to be standard therapies for migraine prevention [196-198]. Though mainly known for its therapeutic effects in CM, onabotulinumtoxin A has been shown positive results in treating TN [199] and refractory, chronic CH [200]. Onabotulinumtoxin A modulates neurotransmitter release, changes in surface expression of receptors and cytokines as well as enhancement of opioidergic transmission [201]. This is done by cleaving synaptosomal nerve-associated protein 
25 (SNAP-25), a vesicle docking protein, within the cell and thus disrupting the fusion of neurotransmitter vesicles to the synaptic cleft [202]. It is likely that onabotulinumtoxin A reduces both peripheral and central sensitization through such mechanisms [203, 204].

\section{Non-pharmacological treatments}

There are currently several non-invasive and invasive stimulation techniques that may help patients who wish to avoid, are refractory to or intolerant of previous drug therapies [108]. Non-invasive stimulation options include the supraorbital stimulation, vagus nerve stimulation (VNS) and the single-pulse transcranial magnetic stimulation [108].

The initial use of VNS to treat headaches first came from the epilepsy field, following several anecdotal reports of migraine improvement in patients with comorbid epilepsy who had been implanted with the device [205]. The vagal nerve is a mixed motor and sensory nerve that is important in controlling autonomic responses; it projects to several higher centres that are important in pain regulation [108]. Indeed, VNS was sufficient to significantly inhibit nocifensive head withdrawal response from mechanical stimulation of V1 trigeminal nociceptors [206]. The commercial use in migraine therapy certainly came with the development of portable devices, which allow to stimulate the vagal nerve transcutaneously at the neck (GammaCore ${ }^{\circ}$ device) or in its auricular portion (Nemos device) in a non-invasive way [205]. Possible uses for VNS is preventative treatment of $\mathrm{CH}$, acute treatment of $\mathrm{CH}$ [207] and preventive treatment of $\mathrm{CM}$ (controlled studies are needed to investigate this point) [208].

The occipital nerves are a target for stimulation due to the anatomical overlap between the trigeminal and cervical afferents in the TCC [108]. This allows stimulation of the occipital region to modulate pain in the trigeminal distribution. Occipital nerve stimulation (ONS) is a surgical procedure where electrodes are placed subcutaneously in the occipital region and then wired to a battery pack in the chest or abdomen [108]. Open-label studies have shown possible efficacy in preventing $\mathrm{CM}$, chronic $\mathrm{CH}$ [209]. Possible uses for ONS is preventative treatment of refractory $\mathrm{CM}$ and chronic $\mathrm{CH}$ [108].

Trigeminal radiofrequency thermocoagulation (TRT) is a surgical intervention used for the treatment of TN. TRT involves puncturing the TG or its branches with a CT- or X-ray-guided a radiofrequency thermocoagulation (RFT) ablation needle [210]. Sensory and motor stimulation are used to replicate the patient's pain and locate and destroy the responsible nerve. Recurrence is possible after RFT ablation; some patients need to continue medication treatment, while others may require reoperation, and postoperative facial numbness is a notable problem combined with developing neuropathic pain [210].

Peripheral nerve blocks (PNB) have been used for the acute and preventive treatment of a variety of primary headache disorders [211]. PNB are generally safe and well-tolerated procedures that may be performed in the outpatient setting [211]. PNB can be used in primary (migraine, $\mathrm{CH}$, and nummular headache) and secondary headaches (cervicogenic headache and headache attributed to craniotomy), as well in cranial neuralgias (trigeminal neuropathies, glossopharyngeal and occipital neuralgias) [179]. This procedure can be necessary for both diagnosis and treatment (e.g a PNB of the inferior dental plexus will halt the pain caused by TN but not a temporomandibular disorder), while in cases it is considered an adjuvant treatment [179]. Interestingly, a retrospective case-study reported long-lasting (1-8 months) and immediate pain-relief for refractory $\mathrm{TN}$ patients treated with PNB [212]. This surprisingly long-lasting result (as the half-life of anaesthetics is usually brief) could be due to the dose-dependent neurotoxicity of local anaesthetics [213].

The block of the greater occipital nerve with an anaesthetic and corticosteroid compound has proved to be effective in the treatment of $\mathrm{CH}$. Regarding the treatment of other headaches and cranial neuralgias, controlled studies are still necessary to clarify the real role of peripheral nerve block [179].

Although nummular headache is characterized by continuous pain in a small circumscribed area, it surprisingly does not respond well to PNB [214], this contrasts to the onabotulinumtoxin $\mathrm{A}$, which seems effective [215]. This suggests that there is difference in the mechanism of a nerve block, and the use of onabotulinumtoxin $\mathrm{A}$.

\section{Conclusion}

The involvement of the fifth cranial nerve in headache has been thoroughly established, following the original postulation by Wolff in the 1940's. The current review summarizes the anatomical and physiological link between headaches, pain perception and the fifth cranial nerve. The most striking evidence comes from the numerous treatments available, where their targets are almost exclusively found in the nerves of trigeminal ganglion; the hub of the fifth cranial nerve. Although we believe that the headache-trigger most likely have the origin in the CNS, this review underscores the importance of trigeminal neurons in the perception of pain. Only when the activation of the fifth cranial nerve is combined with knowledge of central pathological mechanisms, we can start to fully understand the pathology of headache. 


\section{Abbreviations}

CGRP: Calcitonin gene-related peptide; BBB: Blood-brain barrier; TG: Trigeminal ganglion; TN: Trigeminal Neuralgia; WHO: World health organization; TTH: Tension-type headache; $\mathrm{MOH}$ : Medication-overuse headache; CN V: Fifth cranial nerve; V1: Ophthalmic branch; V2: Maxillary branch; V3: Mandibular branch; NGU: Neuronal and glia unit;

ECM: Extracellular matrix; SGC: Satellite glial cell; PACAP: Pituitary adenylate cyclase-activating polypeptide; TCC: Trigeminocervical complex;

TNC: Trigeminal nucleus caudalis; PC: Pars Caudalis; PO: Pars Oralis; PI: Pars Interpolaris; TACs: Trigeminal autonomic cephalalgias; RPON: Recurrent painful ophthalmoplegic neuropathy; MRI: Magnetic resonance imaging; PIFP: persistent idiopathic facial pain; CT: computed tomography; BMLS: burning mouth like syndrome; TRP: Transient receptor potential; TRPV1: TRP vanilloid 1; TRPA1: TRP ankyrin 1; TRPM8: TRP melastatin 8; GWAS: Genome wide association studies; ICHD: International Classification of Headache Disorders; NMDA: N-methyl-D-aspartate; nNOS: neuronal nitric oxide synthase; CH: Cluster Headache; HC: Hemicrania continua; PH: Paroxysmal hemicranias; SUNCT: Short-lasting unilateral neuralgiform headache with conjunctival injection and tearing; SUNA: Short-lasting unilateral neuralgiform headache with cranial autonomic symptoms; C2: Upper cervical root; SSN: Pontine superior salivatory nucleus; COX: Cyclooxygenase; IL- $\beta$ : Interleukin 1 beta; NO: Nitric oxide; 5-HT: 5hydroxytryptamine; FDA: U.S Food and Drug Administration; SNAP25: Synaptosomal nerve-associated protein 25; VNS: Vagus nerve stimulation; ONS: Occipital nerve stimulation; TRT: Trigeminal radiofrequency thermocoagulation; RFT: Radiofrequency thermocoagulation; PNB: Peripheral nerve blocks

\section{Acknowledgements}

This manuscript is a product of the program School of Advanced Studies promoted by the European Headache Federation (EHF-SAS).

\section{Authors' contributions}

All authors contributed equally to the production of this review. All authors read and approved the final manuscript. JE, $A V, A A, E A, R A, C D L, N D E, I F, M K$, $N M, E M, M M, A N, P R, V R, O R, G V$ and $L Z$ are Junior Fellows of EHF-SAS. A. P. Andreou and K. A. Haanes are Senior Fellows of EHF-SAS.

\section{Funding}

The authors received no specific funding for this work.

\section{Availability of data and materials}

Not applicable.

\section{Ethics approval and consent to participate}

Not applicable.

\section{Consent for publication}

Not applicable.

\section{Competing interests}

The authors declare that they have no competing interests.

\section{Author details}

'Department of Clinical Experimental Research, Glostrup Research Institute, Rigshospitalet Glostrup, 2600 Glostrup, Denmark. ${ }^{2}$ Department of Drug Design and Pharmacology, Faculty of Health and Medical Sciences, University of Copenhagen, Copenhagen, Denmark. ${ }^{3}$ RCCS Fondazione Don Carlo Gnocchi, Milan, Italy. ${ }^{4}$ Department of Neurology, First Pavlov State Medical University of St.Petersburg, St.Petersburg, Russia. ${ }^{5} \mathrm{GBUZ}$ Regional Clinical Hospital № 2, Krasnodar, Russia. ${ }^{6}$ Department of Neuroscience, University of Sao Paulo, Ribeirao Preto, Brazil. ${ }^{7}$ Department of Clinical and Experimental Medicine, Neurology Unit, University of Pisa, 56126 Pisa, Italy. ${ }^{8}$ Department of Public Medicine, Laboratory of Morphology of Neuronal Network, University of Campania-Luigi Vanvitelli, Naples, Italy. ${ }^{9}$ Department of Neurology, University of Rome, Tor Vergata, Rome, Italy. ${ }^{10}$ Department of Applied Clinical Sciences and Biotechnology, University of L'Aquila, 67100 L'Aquila, Italy. ${ }^{11}$ Department of Neurosurgery, First Pavlov State Medical University of St.Petersburg, Lev Tolstoy Street 6-8, St.Petersburg, Russia. ${ }^{12}$ The Leningrad Regional State Budgetary Institution of health care "Children's clinical hospital", St.Petersburg, Russia. ${ }^{13}$ Department of Internal Medicine,
Fondazione Policlinico Universitario Agostino Gemelli IRCCS Università Cattolica del Sacro Cuore, Rome, Italy. ${ }^{14}$ Pain Department, Petrovsky National Research Centre of Surgery, Moscow, Russia. ${ }^{15}$ Faculty of Medicine, University of Tartu, Tartu, Estonia. ${ }^{16}$ F.F. Erisman Federal Research Center for Hygiene, Mytishchy, Russia. ${ }^{17}$ Department of Neurology, St. Anne's University Hospital and Faculty of Medicine, Masaryk University, Brno, Czech Republic. ${ }^{18}$ Child Neurology and Psychiatry Unit, Systems Medicine Department, University Hospital Tor Vergata, Viale Oxford 81, 00133 Rome, Italy. ${ }^{19}$ Unità Sanitaria Locale (USL) Umbria 2, Viale VIII Marzo, 05100 Terni, Italy. ${ }^{20}$ Department of Neurology, Headache Center, Ospedale Pediatrico Bambino Gesù, IRCCS, Rome, Italy. ${ }^{21}$ Department of Neurology, ZNA Middelheim, Lindendreef 1, 2020 Antwerp, Belgium. ${ }^{22}$ Department of Anaesthesiology and Intensive Care, Faculty of Medicine, Riga Stradins University, Riga, Latvia. ${ }^{23}$ Department of Pain Medicine, Hospital Jurmala, Jurmala, Latvia. ${ }^{24}$ Headache Centre Vivendi, Riga, Latvia. ${ }^{25}$ Headache Research, Wolfson CARD, Institute of Psychiatry, Psychology and Neuroscience, King's College London, London, UK. ${ }^{26}$ The Headache Centre, Guy's and St Thomas, NHS Foundation Trust, London, UK

Received: 17 March 2020 Accepted: 25 May 2020

Published online: 05 June 2020

\section{References}

1. (2018) Headache Classification Committee of the International Headache Society (IHS) The International Classification of Headache Disorders, 3rd edition. Cephalalgia 38(1):1-211

2. Ray BS, Wolff HG (1940) Experimental studies on headache: pain-sensitive structures of the head and their significance in headache. Arch Surg 41(4): 813-856

3. Silberstein SD, Lipton RB, Dalessio DJ (2001) Wolf's headache and other head pain: Oxford University press

4. Fontaine D, Almairac F, Santucci S, Fernandez C, Dallel R, Pallud J et al (2018) Dural and pial pain-sensitive structures in humans: new inputs from awake craniotomies. Brain 141(4):1040-1048

5. Edvinsson L (2011) Tracing neural connections to pain pathways with relevance to primary headaches. Cephalalgia 31(6):737-747

6. Stovner LJ, Nichols E, Steiner TJ, Abd-Allah F, Abdelalim A, Al-Raddadi RM et al (2018) Global, regional, and national burden of migraine and tensiontype headache, 1990-2016: a systematic analysis for the global burden of disease study 2016. Lancet Neurology 17(11):954-976

7. (2018) Global, regional, and national burden of migraine and tension-type headache, 1990-2016: a systematic analysis for the Global Burden of Disease Study 2016. Lancet Neurology 17(11):954-976

8. James SL, Abate D, Abate KH, Abay SM, Abbafati C, Abbasi N et al (2018) Global, regional, and national incidence, prevalence, and years lived with disability for 354 diseases and injuries for 195 countries and territories, 1990-2017: a systematic analysis for the global burden of disease study 2017. Lancet 392(10159):1789-1858

9. Linde M, Gustavsson A, Stovner LJ, Steiner TJ, Barré J, Katsarava Z et al (2012) The cost of headache disorders in Europe: the Eurolight project. Eur J Neurol 19(5):703-711

10. Feigin VL, et al. (2020) The global burden of neurological disorders: translating evidence into policy Lancet Neurol 19(3):255-265

11. Finnerup NB, Nikolajsen L, Jensen TS (2012) Are we neglecting spinal reorganization following nerve damage? Pain 153(2):269-272

12. Frederiksen SD, Haanes KA, Warfvinge K, Edvinsson L (2019) Perivascular neurotransmitters: regulation of cerebral blood flow and role in primary headaches. J Cereb Blood Flow Metab 39(4):610-632

13. Edvinsson L, Krause D. Cerebral Blood Flow and Metabolism (2002). Philadelphia: Lippincott Williams \& Wilkins 17(521):8

14. Edvinsson $L$ (2017) The Trigeminovascular pathway: role of CGRP and CGRP receptors in migraine. Headache 57(Suppl 2):47-55

15. Noseda R, Burstein R (2013) Migraine pathophysiology: anatomy of the trigeminovascular pathway and associated neurological symptoms, cortical spreading depression, sensitization, and modulation of pain. Pain 154:S44S53

16. Eftekhari S, Salvatore CA, Johansson S, Chen TB, Zeng Z, Edvinsson L (2015) Localization of CGRP, CGRP receptor, PACAP and glutamate in trigeminal ganglion Relation to the blood-brain barrier. Brain Res 1600:93-109

17. Messlinger K, Russo AF (2019) Current understanding of trigeminal ganglion structure and function in headache. Cephalalgia 39(13):1661-1674 
18. Thalakoti S, Patil W, Damodaram S, Vause CV, Langford LE, Freeman SE et al (2007) Neuron-glia signaling in trigeminal ganglion: implications for migraine pathology. Headache 47(7):1008-1023

19. Franceschini $A$, Vilotti $S$, Ferrari MD, van den Maagdenberg AM, Nistri $A$, Fabbretti E (2013) TNFa levels and macrophages expression reflect an inflammatory potential of trigeminal ganglia in a mouse model of familial hemiplegic migraine. PLoS One 8(1):e52394 https://doi.org/10.1371/journal. pone.0052394

20. Harriott AM, Gold MS (2009) Contribution of primary afferent channels to neuropathic pain. Curr Pain Headache Rep 13(3):197-207

21. Bista P, Wendy L (2019) Imlach. "Pathological Mechanisms and Therapeutic Targets for Trigeminal Neuropathic Pain." Medicines 6(3):91

22. Pennisi E, Cruccu G, Manfredi M, Palladini G (1991) Histometric study of myelinated fibers in the human trigeminal nerve. J Neurol Sci 105(1):22-28

23. Jay GW, Barkin RL (2017) Primary headache disorders- part 2: tension-type headache and medication overuse headache. Dis Mon 63(12):342-367

24. Bendtsen $L$ (2003) Central and peripheral sensitization in tension-type headache. Curr Pain Headache Rep 7(6):460-465

25. Fumal A, Schoenen J (2008) Tension-type headache: current research and clinical management. Lancet Neurology. 7(1):70-83

26. Rusu MC, Cretoiu D, Vrapciu AD, Hostiuc S, Dermengiu D, Manoiu VS et al (2016) Telocytes of the human adult trigeminal ganglion. Cell Biol Toxicol 32(3):199-207

27. De Luca C, Colangelo AM, Alberghina L, Papa M (2018) Neuro-immune hemostasis: homeostasis and diseases in the central nervous system. Front Cell Neurosci 12:459

28. Messlinger K (2018) The big CGRP flood - sources, sinks and signalling sites in the trigeminovascular system. J Headache Pain 19(1):22

29. Edvinsson L, Haanes KA, Warfvinge K, Krause DN (2018) CGRP as the target of new migraine therapies - successful translation from bench to clinic. Nat Rev Neurol 14(6):338-350

30. Lundblad C, Haanes KA, Grande G, Edvinsson L (2015) Expeerimental inflammation following dural application of complete Freund's adjuvant or inflammatory soup does not alter brain and trigeminal microvascular passage. J Headache Pain 16:91

31. De Luca C, Savarese L, Colangelo AM, Bianco MR, Cirillo G, Alberghina L et al (2016) Astrocytes and microglia-mediated immune response in maladaptive plasticity is differently modulated by NGF in the ventral horn of the spinal cord following peripheral nerve injury. Cell Mol Neurobiol 36(1):37-46

32. Cirillo G, Colangelo AM, Berbenni M, Ippolito VM, De Luca C, Verdesca F et al (2015) Purinergic modulation of spinal neuroglial maladaptive plasticity following peripheral nerve injury. Mol Neurobiol 52(3):1440-1457

33. Papa M, De Luca C, Petta F, Alberghina L, Cirillo G (2014) Astrocyte-neuron interplay in maladaptive plasticity. Neurosci Biobehav Rev 42:35-54

34. Virtuoso A, Herrera-Rincon C, Papa M, Panetsos F (2019) Dependence of Neuroprosthetic stimulation on the sensory modality of the trigeminal neurons following nerve injury. Implications in the Design of Future Sensory Neuroprostheses for correct perception and modulation of neuropathic pain. Front Neurosci 13:389

35. Takeda M, Takahashi M, Nasu M, Matsumoto S (2011) Peripheral inflammation suppresses inward rectifying potassium currents of satellite glial cells in the trigeminal ganglia. Pain 152(9):2147-2156

36. Lai TH, Protsenko E, Cheng YC, Loggia ML, Coppola G, Chen WT (2015) Neural plasticity in common forms of chronic headaches. Neural Plast 2015: 205985

37. Kawaguchi A, Sato M, Kimura M, Ichinohe T, Tazaki M, Shibukawa Y (2015) Expression and function of purinergic $\mathrm{P} 2 \mathrm{Y} 12$ receptors in rat trigeminal ganglion neurons. Neurosci Res 98:17-27

38. Goto T, Oh SB, Takeda M, Shinoda M, Sato T, Gunjikake KK et al (2016) Recent advances in basic research on the trigeminal ganglion. J Physiol Sci 66(5):381-386

39. Haanes KA, Edvinsson L (2014) Expression and characterization of purinergic receptors in rat middle meningeal artery-potential role in migraine. PLoS One 9(9):e108782

40. Haanes KA, Labastida-Ramírez A, Blixt FW, Rubio-Beltrán E, Dirven CM, Danser AH et al (2019) Exploration of purinergic receptors as potential antimigraine targets using established pre-clinical migraine models. Cephalalgia 39(11):1421-1434

41. Gates P (2006) Duus' topical diagnosis in neurology: anatomy, physiology, signs, symptoms, -by M. Baehr and M. Frotscher. Int Med J 36(9):557
42. Toshida H, Suto C (2018) Preganglionic parasympathetic denervation rabbit model for innervation studies. Cornea 37(Suppl 1):S106-Ss12

43. Morgan C, DeGroat WC, Jannetta PJ (1987) Sympathetic innervation of the cornea from the superior cervical ganglion. An HRP study in the cat. $J$ Auton Nerv Syst 20(2):179-183

44. Suzuki N, Hardebo JE, Owman C (1989) Trigeminal fibre collaterals storing substance $P$ and calcitonin gene-related peptide associate with ganglion cells containing choline acetyltransferase and vasoactive intestinal polypeptide in the sphenopalatine ganglion of the rat. An axon reflex modulating parasympathetic ganglionic activity? Neuroscience 30(3):595-604

45. Larrier D, Lee A (2003) Anatomy of headache and facial pain. Otolaryngol Clin N Am 36(6):1041-1053 v

46. Goadsby PJ, Holland PR, Martins-Oliveira M, Hoffmann J, Schankin C, Akerman S (2017) Pathophysiology of migraine: a disorder of sensory processing. Physiol Rev 97(2):553-622

47. Liu-Chen LY, Han DH, Moskowitz MA (1983) Pia arachnoid contains substance $P$ originating from trigeminal neurons. Neuroscience 9(4):803-808

48. Liu-Chen LY, Mayberg MR, Moskowitz MA (1983) Immunohistochemical evidence for a substance P-containing trigeminovascular pathway to pial arteries in cats. Brain Res 268(1):162-166

49. Mayberg MR, Zervas NT, Moskowitz MA (1984) Trigeminal projections to supratentorial pial and dural blood vessels in cats demonstrated by horseradish peroxidase histochemistry. J Comp Neurol 223(1):46-56

50. Penfield W, McNAUGHTON F (1940) Dural headache and innervation of the dura mater. Arch Neurol Psychiatr 44(1):43-75

51. Anastasi G, Capitani S, Carnazza M, Cinti S, Cremona O, De Caro R, et al. (2010) Trattato di anatomia umana

52. Burchiel KJ (2003) A new classification for facial pain. Neurosurgery 53(5): 1164-1167

53. Donnet A, Simon E, Cuny E, Demarquay G, Ducros A, De Gaalon S et al (2017) French guidelines for diagnosis and treatment of classical trigeminal neuralgia (French headache society and French neurosurgical society). Rev Neurol (Paris) 173(3):131-151

54. Brazis PW, Masdeu JC (2011) Localization in Clinical Neurology (sixth ed.), Philadelphia: Lippincott Williams \& Wilkins

55. Piovesan EJ, Kowacs PA, Oshinsky ML (2003) Convergence of cervical and trigeminal sensory afferents. Curr Pain Headache Rep 7(5):377-383

56. Haines DE, Mihailoff GA (2017) Fundamental neuroscience for Basic and clinical applications E-book: Elsevier health sciences

57. Fisch A (2012) Neuroanatomy: draw it to know it: OUP USA

58. Rusu MC (2004) The spinal trigeminal nucleus-considerations on the structure of the nucleus caudalis. Folia Morphol (Warsz) 63(3):325-328

59. Pradier B, McCormick SJ, Tsuda AC, Chen RW, Atkinson AL, Westrick MR et al (2019) Properties of neurons in the superficial laminae of trigeminal nucleus caudalis. Physiol Rep 7(12):e14112

60. Noseda R, Jakubowski M, Kainz V, Borsook D, Burstein R (2011) Cortical projections of functionally identified thalamic trigeminovascular neurons: implications for migraine headache and its associated symptoms. J Neurosci 31(40):14204-14217

61. Malick A, Strassman RM, Burstein R (2000) Trigeminohypothalamic and reticulohypothalamic tract neurons in the upper cervical spinal cord and caudal medulla of the rat. J Neurophysiol 84(4):2078-2112

62. Almeida TF, Roizenblatt S, Tufik S (2004) Afferent pain pathways: a neuroanatomical review. Brain Res 1000(1-2):40-56

63. Patel NM, Das JM (2019) Neuroanatomy, Spinal Trigeminal Nucleus. StatPearls Publishing, StatPearls

64. Kocorowski LH, Helmstetter FJ (2001) Calcitonin gene-related peptide released within the amygdala is involved in Pavlovian auditory fear conditioning. Neurobiol Learn Mem 75(2):149-163

65. Palmiter RD (2018) The parabrachial nucleus: CGRP neurons function as a general alarm. Trends Neurosci 41(5):280-293

66. Han JS, Li W, Neugebauer V (2005) Critical role of calcitonin gene-related peptide 1 receptors in the amygdala in synaptic plasticity and pain behavior. J Neurosci 25(46):10717-10728

67. Shinohara K, Watabe AM, Nagase M, Okutsu Y, Takahashi Y, Kurihara H et al (2017) Essential role of endogenous calcitonin gene-related peptide in painassociated plasticity in the central amygdala. Eur J Neurosci 46(6):2149-2160

68. Missig G, Mei L, Vizzard MA, Braas KM, Waschek JA, Ressler KJ et al (2017) Parabrachial pituitary adenylate cyclase-activating polypeptide activation of amygdala endosomal extracellular signal-regulated kinase signaling regulates the emotional component of pain. Biol Psychiatry 81(8):671-682 
69. Sohn JH, Choi HC, Kim CH (2013) Differences between episodic and chronic tension-type headaches in nociceptive-specific trigeminal pathways. Cephalalgia 33(5):330-339

70. Schwartz BS, Stewart WF, Simon D, Lipton RB (1998) Epidemiology of tension-type headache. Jama 279(5):381-383

71. Bendtsen $L$ (2000) Central sensitization in tension-type headache--possible pathophysiological mechanisms. Cephalalgia 20(5):486-508

72. May A, Burstein R (2019) Hypothalamic regulation of headache and migraine. Cephalalgia 39(13):1710-1719

73. Goadsby PJ (2009) The vascular theory of migraine--a great story wrecked by the facts. Brain 132(Pt 1):6-7

74. Amin FM, Asghar MS, Hougaard A, Hansen AE, Larsen VA, de Koning PJ et al (2013) Magnetic resonance angiography of intracranial and extracranial arteries in patients with spontaneous migraine without aura: a crosssectional study. Lancet Neurology 12(5):454-461

75. Charles A (2013) Vasodilation out of the picture as a cause of migraine headache. Lancet Neurology 12(5):419-420

76. Goadsby P, Edvinsson L, Ekman R (1988) Release of vasoactive peptides in the extracerebral circulation of humans and the cat during activation of the trigeminovascular system. Ann Neurol 23(2):193-196

77. Tuka B, Helyes Z, Markovics A, Bagoly T, Németh J, Márk L et al (2012) Peripheral and central alterations of pituitary adenylate cyclase activating polypeptide-like immunoreactivity in the rat in response to activation of the trigeminovascular system. Peptides 33(2):307-316

78. Lassen L, Haderslev P, Jacobsen V, Iversen HK, Sperling B, Olesen J (2002) CGRP may play a causative role in migraine. Cephalalgia 22(1):54-61

79. Olesen J, Burstein R, Ashina M, Tfelt-Hansen P (2009) Origin of pain in migraine: evidence for peripheral sensitisation. Lancet Neurology 8(7):679_ 690

80. Hou M, Uddman R, Tajti J, Kanje M, Edvinsson L (2002) Capsaicin receptor immunoreactivity in the human trigeminal ganglion. Neurosci Lett 330(3): 223-226

81. Benemei S, Fusi C, Trevisan G, Geppetti P (2014) The TRPA1 channel in migraine mechanism and treatment. Br J Pharmacol 171(10):2552-2567

82. Dussor G, Cao YQ (2016) TRPM8 and migraine. Headache 56(9):1406-1417

83. Vigano A, Manica A, Di Piero V, Leonardi M (2019) Did going north give us migraine? An evolutionary approach on understanding latitudinal differences in migraine epidemiology. Headache 59(4):632-634

84. Malick A, Burstein R (2000) Peripheral and central sensitization during migraine. Funct Neurol 15:28-35

85. Aurora SK, Brin MF (2017) Chronic migraine: an update on physiology, imaging, and the mechanism of action of two available pharmacologic therapies. Headache 57(1):109-125

86. Moskowitz MA (2008) Defining a pathway to discovery from bench to bedside: the trigeminovascular system and sensitization. Headache 48(5): 688-690

87. Burstein R, Jakubowski M, Garcia-Nicas E, Kainz V, Bajwa Z, Hargreaves R et al (2010) Thalamic sensitization transforms localized pain into widespread allodynia. Ann Neurol 68(1):81-91

88. Cernuda-Morollón E, Larrosa D, Ramón C, Vega J, Martínez-Camblor P, Pascual J (2013) Interictal increase of CGRP levels in peripheral blood as a biomarker for chronic migraine. Neurology 81(14):1191-1196

89. Edvinsson L, Haanes KA, Warfvinge K (2019) Does inflammation have a role in migraine? Nat Rev Neurol 15(8):483-490

90. Goadsby P, Edvinsson L, Ekman R (1990) Vasoactive peptide release in the extracerebral circulation of humans during migraine headache. Ann Neurology 28(2):183-187

91. Lukács M, Haanes KA, Majláth Z, Tajti J, Vécsei L, Warfvinge K et al (2015) Dural administration of inflammatory soup or complete Freund's adjuvant induces activation and inflammatory response in the rat trigeminal ganglion. J Headache Pain 16(1):79

92. Fernandez-de-las-Penas C, Cuadrado ML, Arendt-Nielsen L, Simons DG, Pareja JA (2007) Myofascial trigger points and sensitization: an updated pain model for tension-type headache. Cephalalgia 27(5):383-393

93. Groves PM, Thompson RF (1970) Habituation: a dual-process theory. Psychol Rev 77(5):419-450

94. Coppola G, Di Lorenzo C, Schoenen J, Pierelli F (2013) Habituation and sensitization in primary headaches. J Headache Pain 14:65

95. Perrotta A, Serrao M, Sandrini G, Bogdanova D, Tassorelli C, Bartolo M et al (2008) Reduced habituation of trigeminal reflexes in patients with episodic cluster headache during cluster period. Cephalalgia 28(9):950-959
96. Lee J, Lin RL, Garcia RG, Kim J, Kim H, Loggia ML et al (2017) Reduced insula habituation associated with amplification of trigeminal brainstem input in migraine. Cephalalgia 37(11):1026-1038

97. Diener HC, Dodick D, Evers S, Holle D, Jensen RH, Lipton RB et al (2019) Pathophysiology, prevention, and treatment of medication overuse headache. Lancet Neurology 18(9):891-902

98. Diener HC, Holle D, Solbach K, Gaul C (2016) Medication-overuse headache: risk factors, pathophysiology and management. Nat Rev Neurol 12(10):575583

99. Supornsilpchai W, le Grand SM, Srikiatkhachorn A (2010) Cortical hyperexcitability and mechanism of medication-overuse headache. Cephalalgia 30(9):1101-1109

100. Okada-Ogawa A, Porreca F, Meng ID (2009) Sustained morphine-induced sensitization and loss of diffuse noxious inhibitory controls in dura-sensitive medullary dorsal horn neurons. J Neurosci 29(50):15828-15835

101. Srikiatkhachorn A, Anthony M (1996) Platelet serotonin in patients with analgesic-induced headache. Cephalalgia 16(6):423-426

102. Coppola G, Currà A, Di Lorenzo C, Parisi V, Gorini M, Sava SL et al (2010) Abnormal cortical responses to somatosensory stimulation in medicationoveruse headache. BMC Neurol 10(1):126

103. Viganò A, Torrieri MC, Toscano M, Puledda F, Petolicchio B, D'Elia TS et al (2018) Neurophysiological correlates of clinical improvement after greater occipital nerve (GON) block in chronic migraine: relevance for chronic migraine pathophysiology. J Headache Pain 19(1):73

104. Wei DY-T, Ong JJY, Goadsby PJ (2018) Overview of trigeminal autonomic cephalalgias: Nosologic evolution, diagnosis, and management. Ann Indian Acad Neurol 21(Suppl 1):S39

105. Tuka B, Szabó N, Tóth E, Kincses ZT, Párdutz Á, Szok D et al (2016) Release of PACAP-38 in episodic cluster headache patients-an exploratory study. Headache Pain 17(1):69

106. Goadsby PJ, Edvinsson L (1994) Human in vivo evidence for trigeminovascular activation in cluster headache neuropeptide changes and effects of acute attacks therapies. Brain 117(3):427-434

107. Goadsby PJ, Dodick DW, Leone M, Bardos JN, Oakes TM, Millen BA et al (2019) Trial of Galcanezumab in prevention of episodic cluster headache. N Engl J Med 381(2):132-141

108. Miller S, Sinclair AJ, Davies B, Matharu M (2016) Neurostimulation in the treatment of primary headaches. Pract Neurol 16(5):362-375

109. May A, Schwedt TJ, Magis D, Pozo-Rosich P, Evers S, Wang S-J (2018) Cluster headache. Nat Reviews Dis Prime 4:18006

110. Akerman S, Holland PR, Summ O, Lasalandra MP, Goadsby PJ (2012) A translational in vivo model of trigeminal autonomic cephalalgias: therapeutic characterization. Brain 135(12):3664-3675

111. Schoenen J, Jensen RH, Lanteri-Minet M, Láinez MJ, Gaul C, Goodman AM et al (2013) Stimulation of the sphenopalatine ganglion (SPG) for cluster headache treatment. Pathway $\mathrm{CH}-1$ : a randomized, sham-controlled study. Cephalalgia 33(10):816-830

112. Cohen A (2017) SUN: short-lasting unilateral neuralgiform headache attacks. Headache 57(6):1010-1020

113. Pedersen JL, Barloese M, Jensen RH (2013) Neurostimulation in cluster headache: a review of current progress. Cephalalgia 33(14):1179-1193

114. Snoer A, Lund N, Beske R, Hagedorn A, Jensen RH, Barloese M (2018) Cluster headache beyond the pain phase: a prospective study of 500 attacks. Neurology 91(9):e822-ee31

115. Merskey HE (1986) Classification of chronic pain: descriptions of chronic pain syndromes and definitions of pain terms. Pain 3:S1-226

116. Maarbjerg S, Di Stefano G, Bendtsen L, Cruccu G (2017) Trigeminal neuralgia-diagnosis and treatment. Cephalalgia 37(7):648-657

117. Evers S (2017) Facial pain: overlapping syndromes. Cephalalgia 37(7):705713

118. Huang C, Amasanti M, Lovell B, Young T (2017) Recurrent painful ophthalmoplegic neuropathy. Pract Neurol 17(4):318-320

119. Evans RW, Pareja JA (2009) Expert opinion. Supraorbital neuralgia. Headache 49(2):278-281

120. Pareja JA, Lopez-Ruiz P, Mayo D, Villar-Quiles RN, Carcamo A, GutierrezViedma A et al (2017) Supratrochlear neuralgia: a prospective case series of 15 patients. Headache 57(9):1433-1442

121. Pareja JA, Cuadrado ML (2013) Lacrimal neuralgia: so far, a missing crania neuralgia. Cephalalgia 33(14):1198-1202

122. Tran TM, McClelland CM, Lee MS (2019) Diagnosis and Management of Trochleodynia, Trochleitis, and trochlear headache. Front Neurol 10:361 
123. Pareja JA, Cuadrado ML, Porta-Etessam J, Fernandez-de-las-Penas C, Gili P, Caminero AB et al (2010) Idiopathic ophthalmodynia and idiopathic rhinalgia: two topographic facial pain syndromes. Headache 50(8):12861295

124. Razek AA, Castillo M (2009) Imaging lesions of the cavernous sinus. AJNR Am J Neuroradiol 30(3):444-452

125. Caldarelli C, Benech R, laquinta C (2016) Superior orbital fissure syndrome in lateral Orbital Wall fracture: management and classification update. Craniomaxillofac Trauma Reconstr 9(4):277-283

126. Bendtsen L, Zakrzewska JM, Abbott J, Braschinsky M, Di Stefano G, Donnet A et al (2019) European academy of neurology guideline on trigeminal neuralgia. Eur J Neurol 26(6):831-849

127. Maarbjerg S, Gozalov A, Olesen J, Bendtsen L (2014) Trigeminal neuralgia-a prospective systematic study of clinical characteristics in 158 patients. Headache 54(10):1574-1582

128. Maarbjerg S, Wolfram F, Gozalov A, Olesen J, Bendtsen L (2015) Significance of neurovascular contact in classical trigeminal neuralgia. Brain 138(2):311-319

129. Obermann M, Rodriguez-Raecke R, Naegel S, Holle D, Mueller D, Yoon M-S et al (2013) Gray matter volume reduction reflects chronic pain in trigeminal neuralgia. Neuroimage 74:352-358

130. Tian T, Guo L, Xu J, Zhang S, Shi J, Liu C et al (2016) Brain white matter plasticity and functional reorganization underlying the central pathogenesis of trigeminal neuralgia. Sci Rep 6:36030

131. Leal PRL, Barbier C, Hermier M, Souza MA, Cristino-Filho G, Sindou M (2014) Atrophic changes in the trigeminal nerves of patients with trigeminal neuralgia due to neurovascular compression and their association with the severity of compression and clinical outcomes. J Neurosurg 120(6):1484-1495

132. Benoliel R, Gaul C (2017) Persistent idiopathic facial pain. Cephalalgia 37(7): 680-691

133. Forssell H, Tenovuo O, Silvoniemi P, Jaaskelainen SK (2007) Differences and similarities between atypical facial pain and trigeminal neuropathic pain. Neurology 69(14):1451-1459

134. Lang E, Kaltenhauser M, Seidler S, Mattenklodt P, Neundorfer B (2005) Persistent idiopathic facial pain exists independent of somatosensory input from the painful region: findings from quantitative sensory functions and somatotopy of the primary somatosensory cortex. Pain 118(1-2):80-91

135. Du B, Xu J, Hu J, Zhong X, Liang J, Lei P et al (2019) A clinical study of the intra-Neuroendoscopic technique for the treatment of subacute-chronic and chronic septal subdural hematoma. Front Neurol 10:1408

136. Moazzam AA, Habibian M (2012) Patients appearing to dental professionals with orofacial pain arising from intracranial tumors: a literature review. Oral Surg Oral Med Oral Pathol Oral Radiol 114(6):749-755

137. List T, Leijon G, Svensson P (2008) Somatosensory abnormalities in atypical odontalgia: a case-control study. Pain 139(2):333-341

138. Klasser GD, Grushka M, Su N (2016) Burning mouth syndrome. Oral Maxillofac Surg Clin North Am 28(3):381-396

139. Campbell WW Jr (1986) The numb cheek syndrome: a sign of infraorbital neuropathy. Neurology. 36(3):421-423

140. Lopez Mesonero L, Pedraza Hueso Ml, Herrero Velazquez S, Guerrero Peral AL (2014) Infraorbital neuralgia: a diagnostic possibility in patients with zygomatic arch pain. Neurologia 29(6):381-382

141. Okholm C, Frendo M, Kiss K, von Buchwald C (2018) Cheek numbness caused by Perineural tumor invasion of the infraorbital nerve: a review of 3 diagnostically challenging cases. Am J Case Rep 19:296-300

142. Cesarik M, Zavoreo I, Zadro-Matovina L, Papic M, Basic KV (2016) Effects of trigeminal nerve dysfunction in various types of headaches. Coll Antropol 40(3):183-188

143. Goadsby PJ (2019) Primary headache disorders: five new things. Neurol Clin Pract 9(3):233-240

144. Antony AB, Mazzola AJ, Dhaliwal GS, Hunter CW (2019) Neurostimulation for the treatment of chronic head and facial pain: a literature review. Pain Physician 22(5):447-477

145. Hascalovici JR, Robbins MS (2017) Peripheral nerve blocks for the treatment of headache in older adults: a retrospective study. Headache 57(1):80-86

146. Coculescu EC, Radu A, Coculescu BI (2014) Burning mouth syndrome: a review on diagnosis and treatment. J Med Life 7(4):512-515

147. Aryeh HB, Gottlieb I, Ish-Shalom S, David A, Szargel H, Laufer D (1996) Oral complaints related to menopause. Maturitas 24(3):185-189

148. Klasser GD, Fischer DJ, Epstein JB (2008) Burning mouth syndrome: recognition, understanding, and management. Oral Maxillofac Surg Clin North Am 20(2):255-271 vii
149. Lauria G, Majorana A, Borgna M, Lombardi R, Penza P, Padovani A et al (2005) Trigeminal small-fiber sensory neuropathy causes burning mouth syndrome. Pain. 115(3):332-337

150. Jaaskelainen SK, Woda A (2017) Burning mouth syndrome. Cephalalgia 37(7):627-647

151. Heckmann SM, Kirchner E, Grushka M, Wichmann MG, Hummel T (2012) A double-blind study on clonazepam in patients with burning mouth syndrome. Laryngoscope 122(4):813-816

152. Cui Y, Xu H, Chen F, Liu J, Jiang L, Zhou Y et al (2016) Efficacy evaluation of clonazepam for symptom remission in burning mouth syndrome: a metaanalysis. Oral Dis 22(6):503-511

153. Baskaran RK, Krishnamoorthy SM (2006) Numb chin syndrome--a reflection of systemic malignancy. World J Surg Oncol 4:52

154. Murphy MK, MacBarb RF, Wong ME, Athanasiou KA (2013) Temporomandibular disorders: a review of etiology, clinical management, and tissue engineering strategies. Int J Oral Maxillofac Implants 28(6):e393-e414

155. Pihut M, Szuta M, Ferendiuk E, Zenczak-Wieckiewicz D (2014) Differentia diagnostics of pain in the course of trigeminal neuralgia and temporomandibular joint dysfunction. Biomed Res Int 2014:563786

156. Haanes KA, Edvinsson L (2019) Pathophysiological mechanisms in migraine and the identification of new therapeutic targets. CNS Drugs 33(6):525-537

157. Kröger IL, May A (2014) Central effects of acetylsalicylic acid on trigeminalnociceptive stimuli. J Headache Pain. 15(1):59

158. Khoury CK, Couch JR (2010) Sumatriptan-naproxen fixed combination for acute treatment of migraine: a critical appraisal. Drug Des Dev Ther 4:9

159. Baraldi C, Pellesi L, Guerzoni S, Cainazzo MM, Pini LA (2017) Therapeutical approaches to paroxysmal hemicrania, hemicrania continua and short lasting unilateral neuralgiform headache attacks: a critical appraisal. J Headache Pain 18(1):71

160. Sjaastad O (2006) Chronic paroxysmal hemicrania: from the index patient to the disease. Curr Pain Headache Rep 10(4):295-301

161. Neeb L, Hellen P, Boehnke C, Hoffmann J, Schuh-Hofer S, Dirnagl U et al (2011) IL-1 $\beta$ stimulates COX-2 dependent PGE2 synthesis and CGRP release in rat trigeminal ganglia cells. PLoS One 6(3):e17360

162. Summ O, Evers S (2013) Mechanism of action of indomethacin in indomethacin-responsive headaches. Curr Pain Headache Rep 17(4):327

163. Summ O, Andreou AP, Akerman S, Goadsby PJ (2010) A potential nitrergic mechanism of action for indomethacin, but not of other COX inhibitors: relevance to indomethacin-sensitive headaches. J Headache Pain 11(6):477-483

164. VanderPluym J (2015) Indomethacin-responsive headaches. Curr Neurol Neurosci Rep 15(2):516

165. Akerman S, Holland PR, Summ O, Lasalandra MP, Goadsby PJ (2012) A translational in vivo model of trigeminal autonomic cephalalgias: therapeutic characterization. Brain 135(Pt 12):3664-3675

166. Edvinsson L, Villalón CM, MaassenVanDenBrink A (2012) Basic mechanisms of migraine and its acute treatment. Pharmacol Ther 136(3):319-333

167. Edvinsson JCA, Warfvinge K, Krause DN, Blixt FW, Sheykhzade M, Edvinsson L et al (2019) C-fibers may modulate adjacent Adelta-fibers through axonaxon CGRP signaling at nodes of Ranvier in the trigeminal system. J Headache Pain 20(1):105

168. Arvieu L, Mauborgne A, Bourgoin S, Oliver C, Feltz P, Hamon M et al (1996) Sumatriptan inhibits the release of CGRP and substance $P$ from the rat spinal cord. Neuroreport 7(12):1973-1976

169. Silberstein SD, McCrory DC (2003) Ergotamine and dihydroergotamine: history, pharmacology, and efficacy. Headache 43(2):144-166

170. Rubio-Beltrán E, Labastida-Ramírez A, Villalón CM, MaassenVanDenBrink A (2018) Is selective 5-HT1F receptor agonism an entity apart from that of the triptans in antimigraine therapy? Pharmacol Ther 186:88-97

171. Kröger IL, May A (2015) Triptan-induced disruption of trigemino-cortical connectivity. Neurology 84(21):2124-2131

172. Burish MJ, Rozen TD (2019) Trigeminal Autonomic Cephalalgias. Neurol Clin 37(4):847-869

173. Moore D, et al (2019) "A systematic review of rescue analgesic strategies in acute exacerbations of primary trigeminal neuralgia." Br J Anaesth 123.2: e385-e396

174. Vila-Pueyo M (2018) Targeted 5-HT $1 F$ therapies for migraine. Neurotherapeutics 15(2):291-303

175. Labastida-Ramírez A, Rubio-Beltrán E, Haanes KA, et al(2020) Lasmiditan inhibits calcitonin gene-related peptide release in the rodent trigeminovascular system. Pain. 161(5):1092-1099 https://doi.org/10.1097/j. pain.0000000000001801 
176. Curto M, Cipolla F, Cisale GY, Capi M, Spuntarelli V, Guglielmetti M et al (2020) Profiling lasmiditan as a treatment option for migraine. Expert Opin Pharmacother 21(2):147-153.

177. Walker CS, Raddant AC, Woolley MJ, Russo AF, Hay DL (2018) CGRP receptor antagonist activity of olcegepant depends on the signalling pathway measured. Cephalalgia 38(3):437-451

178. Scott LJ (2020) Ubrogepant: First Approval. Drugs 80(3):323-328.)

179. Dach F, Éckeli ÁL, Ferreira KS, Speciali JG (2015) Nerve block for the treatment of headaches and cranial neuralgias-a practical approach. Headache 55:59-71

180. Bussone G, Rapoport A (2010) Acute and preventive treatment of cluster headache and other trigeminal autonomic cephalgias. Handbook Clin Neurol 97:431-442

181. Jürgens TP (2014) Therapie des trigeminoautonomen Kopfschmerzes. Bundesgesundheitsblatt-Gesundheitsforschung-Gesundheitsschutz. 57(8): 983-995

182. Obermann M (2010) Treatment options in trigeminal neuralgia. Ther Adv Neurol Disord 3(2):107-115

183. Linde M, Mulleners WM, Chronicle EP, McCrory DC (2013) Antiepileptics other than gabapentin, pregabalin, topiramate, and valproate for the prophylaxis of episodic migraine in adults. Cochrane Database Syst Rev 6: CD010608.

184. Suzuki-Muromoto S, Kosaki R, Kosaki K, Kubota M (2020) Familial hemiplegic migraine with a PRRT2 mutation: phenotypic variations and carbamazepine efficacy. Brain and Development 42(3):293-297

185. Parikh SK, Silberstein SD (2019) Current status of antiepileptic drugs as preventive migraine therapy. Curr Treat Options Neurol 21(4):16

186. Barbanti P, Egeo G, Mitsikostas DD (2019) Trigeminal-targeted treatments in migraine: is 60\% the magic number? Headache 59(9):1659-1661

187. Deen M, Correnti E, Kamm K, Kelderman T, Papetti L, Rubio-Beltrán E et al (2017) Blocking CGRP in migraine patients-a review of pros and cons. J Headache 18(1):96

188. Melo-Carrillo A, Strassman AM, Nir R-R, Schain AJ, Noseda R, Stratton J et al (2017) Fremanezumab—a humanized monoclonal anti-CGRP antibody -inhibits thinly myelinated (Aס) but not unmyelinated (C) meningeal nociceptors. J Neurosci 37(44):10587-10596

189. Yuan H, Lauritsen CG, Kaiser EA, Silberstein SD (2017) CGRP monoclonal antibodies for migraine: rationale and progress. BioDrugs 31(6):487-501

190. Noseda R, Schain AJ, Melo-Carrillo A, Tien J, Stratton J, Mai F et al (2020) Fluorescently-labeled fremanezumab is distributed to sensory and autonomic ganglia and the dura but not to the brain of rats with uncompromised blood brain barrier. Cephalalgia 40(3):229-240

191. Charles A (2018) The pathophysiology of migraine: implications for clinical management. Lancet Neurol 17(2):174-182

192. Edvinsson L (2015) CGRP receptor antagonists and antibodies against CGRP and its receptor in migraine treatment. Br J Clin Pharmacol 80(2):193-199

193. Sacco S, Bendtsen L, Ashina M, Reuter U, Terwindt G, Mitsikostas D-D et al (2019) European headache federation guideline on the use of monoclonal antibodies acting on the calcitonin gene related peptide or its receptor for migraine prevention. J Headache Pain. 20(1):6

194. Melo-Carrillo A, Noseda R, Nir R-R, Schain AJ, Stratton J, Strassman AM et a (2017) Selective inhibition of trigeminovascular neurons by fremanezumab: a humanized monoclonal anti-CGRP antibody. J Neurosci 37(30):7149-7163

195. Goadsby P, Edvinsson L (1996) Neuropeptide changes in a case of chronic paroxysmal hemicrania-evidence for trigemino-parasympathetic activation. Cephalalgia 16(6):448-450

196. Lai KL, Niddam D, Fuh JL, Chen SP, Wang YF, Chen WT et al (2017) Flunarizine versus topiramate for chronic migraine prophylaxis: a randomized trial. Acta Neurol Scand 135(4):476-483

197. Silberstein S, Holland S, Freitag F, Dodick DW, Argoff C, Ashman E (2012) Evidence-based guideline update: pharmacologic treatment for episodic migraine prevention in adults: report of the quality standards Subcommittee of the American Academy of neurology and the American headache society. Neurology 78(17):1337-1345

198. Pringsheim T, Davenport W, Mackie G, Worthington I, Aubé M, Christie SN et al (2012) Canadian headache society guideline for migraine prophylaxis. Can J Neurol Sci 39(2 Suppl 2):S1-S59

199. Guardiani E, Sadoughi B, Blitzer A, Sirois D (2014) A new treatment paradigm for trigeminal neuralgia using botulinum toxin type a. Laryngoscope 124(2):413-417
200. Lampl C, Rudolph M, Bräutigam E (2018) OnabotulinumtoxinA in the treatment of refractory chronic cluster headache. J Headache Pain 19(1):45

201. Do T, Hvedstrup J, Schytz H (2018) Botulinum toxin: a review of the mode of action in migraine. Acta Neurol Scand 137(5):442-451

202. Edvinsson J, Warfvinge K, Edvinsson L (2015) Modulation of inflammatory mediators in the trigeminal ganglion by botulinum neurotoxin type a: an organ culture study. J Headache Pain 16:555

203. Gooriah R, Ahmed F (2015) OnabotulinumtoxinA for chronic migraine: a critical appraisal. Therap Clin Risk Manage 11:1003

204. Gazerani P, Pedersen NS, Staahl C, Drewes AM, Arendt-Nielsen L (2009) Subcutaneous botulinum toxin type a reduces capsaicin-induced trigeminal pain and vasomotor reactions in human skin. Pain 141(1-2):60-69

205. Viganò A, Toscano M, Puledda F, Di Piero V (2019) Treating Chronic Migraine With Neuromodulation: The Role of Neurophysiological Abnormalities and Maladaptive Plasticity. Front Pharmacol 10:32. https://doi. org/10.3389/fphar.2019.00032

206. Hawkins JL, Cornelison LE, Blankenship BA, Durham PL (2017) Vagus nerve stimulation inhibits trigeminal nociception in a rodent model of episodic migraine. Pain Rep 2(6):e628 https://doi.org/10.1097/PR9.0000000000000628

207. Gaul C, Diener H, Solbach K, Silver N, Straube A, Magis D et al (2014) EHMTL0364. Non-invasive vagus nerve stimulation using gammacore ${ }^{\oplus}$ for prevention and acute treatment of chronic cluster headache: report from the randomized phase of the preva study. J Headache Pain 15(1)

208. Silberstein SD, Da Silva AN, Calhoun AH, Grosberg BM, Lipton RB, Cady RK,Goadsby PJ, Simmons K, Mullin C, Saper JR, Liebler EJ (2014) Noninvasive Vagus NerveStimulation for Chronic Migraine Prevention in a Prospective, Randomized, Sham-Controlled Pilot Study (the EVENT Study): report from thedouble-blind phase. Headache 54:1426

209. Magis D, Schoenen J (2012) Advances and challenges in neurostimulation for headaches. Lancet Neurology 11(8):708-719

210. Li Y, Yang L, Ni J, Dou Z (2019) Microvascular decompression and radiofrequency for the treatment of trigeminal neuralgia: a meta-analysis. J Pain Res 12:1937

211. Blumenfeld A, Ashkenazi A, Napchan U, Bender SD, Klein BC, Berliner R et al (2013) Expert consensus recommendations for the performance of peripheral nerve blocks for headaches-a narrative review. Headache 53(3): 437-446

212. Perloff MD, Chung JS (2018) Urgent care peripheral nerve blocks for refractory trigeminal neuralgia. Am J Emerg Med 36(11):2058-2060

213. Verlinde M, Hollmann MW, Stevens MF, Hermanns H, Werdehausen R, Lirk P (2016) Local anesthetic-induced neurotoxicity. Int J Mol Sci 17(3):339

214. Dach F, Eckeli AL, Ferreira Kdos S, Speciali JG (2015) Nerve block for the treatment of headaches and cranial neuralgias - a practical approach. Headache 55(Suppl 1):59-71

215. Mathew NT, Kailasam J, Meadors L (2008) Botulinum toxin type a for the treatment of nummular headache: four case studies. Headache 48(3):442447

\section{Publisher's Note}

Springer Nature remains neutral with regard to jurisdictional claims in published maps and institutional affiliations.

Ready to submit your research? Choose BMC and benefit from:

- fast, convenient online submission

- thorough peer review by experienced researchers in your field

- rapid publication on acceptance

- support for research data, including large and complex data types

- gold Open Access which fosters wider collaboration and increased citations

- maximum visibility for your research: over $100 \mathrm{M}$ website views per year

At $\mathrm{BMC}$, research is always in progress.

Learn more biomedcentral.com/submissions 